\title{
Optimizing Two-Dimensional Renewable Warranty Policies for Sensor Embedded Remanufactured Products
}

\author{
Ammar Alqahtani ${ }^{1}$ iD, Surendra M. Gupta ${ }^{2}$ iD \\ ${ }^{1}$ King Abdulaziz University (Saudi Arabia) \\ ${ }^{2}$ Northeastern University (United States) \\ aavlgabtani@,kau.edu.sa, s.gupta@,northeastern.edu
}

Received: November 2016

Accepted: January 2017

\section{Abstract:}

Purpose: Remanufactured products, in addition to being environment friendly, are popular with consumers because they can offer the latest technology with lower prices in comparison to brand new products. However, some consumers are hesitant to buy remanufactured products because they are skeptical about the quality of the remanufactured product and thus are unsure of the extent to which the product will render services when compared to a new product. A strategy that remanufacturers may employ to entice customers is to offer warranties on remanufactured products. To that end, this paper studies and scrutinizes the impact of offering renewing warranties on remanufactured products. Specifically, the paper suggests a methodology which simultaneously minimizes the cost incurred by the remanufacturers and maximizes the confidence of the consumers towards buying remanufacturing products.

Design/methodology/approach: This study uses discrete-event simulation to optimize the implementation of a two-dimensional renewing warranty policy for remanufactured products. The implementation is illustrated using a specific product recovery system called the Advanced Remanufacturing-To-Order (ARTO) system. The experiments used in the study were designed using Taguchi's Orthogonal Arrays to represent the entire domain of the recovery system so as to observe the system behavior under various experimental conditions. In order to determine the optimum strategy offered by the remanufacturer, various warranty and preventive maintenance 
scenarios were analyzed using pairwise $t$-tests along with one-way analysis of variance (ANOVA) and Tukey pairwise comparisons tests for every scenario.

Findings: The proposed methodology is able to simultaneously minimize the cost incurred by the remanufacturer, optimize the warranty price and period, and optimize the preventive maintenance strategy resulting in increased consumer confidence.

Originality/value: This is the first study that evaluates in a quantitative and comprehensive manner the potential benefits of offering warranties with preventive maintenance on remanufactured products.

Keywords: reverse supply chain, preventive maintenance, renewable warranty policies, remanufacturing, sensor embedded products, extending product life-cycle

\section{Introduction}

In current times, the exponential rise in technological development and the customers' desire to repeatedly purchase newer device models and technological products is the impetus which culminates into diminished product life cycles and an upturn in their rate of disposal. As a result, landfill areas and the Earth's natural resources start reaching a critical apex. Therefore, when a technological device reaches the end of its life and becomes essentially no longer useful or just antiquated, manufacturing firms repossess these same products that they had produced prior, in order to manage to meet the new regulations imposed upon them and to enlighten customers' awareness of the pertinent environmental issues regarding this matter. The manufacturers of these technological devices construct specialized facilities specifically designed for the end-of-life (EOL) product recovery process in order to minimize the amount of mechanical waste sent to landfills. This is achieved by retrieving the mechanical materials, parts, and components from the end-of-life products (EOLPs) by way of the recycling, refurbishing, and remanufacturing processes. The economic benefits from such facilities make the process of product recovery more attractive.

In product recovery, disassembly is the most vital operation because it allows for the extraction of the desired components, subassemblies and materials from EOL products. There are various ways to execute the process of disassembling EOL products. They can be effectuated at a single workstation, in a disassembly cell, or on a disassembly line. Although utilizing single workstations and disassembly cells are more flexible, the operation that produces the highest yield is the disassembly line, which is also the most efficient operation for automated disassembly (Gungor \& Gupta, 2002). 
The first fundamental step in the processes of remanufacturing, recycling, and disposing of EOL products is the pertinent operation of product disassembly. Disassembly is the method of deconstructing an EOL product down to its core mechanical components by utilizing either non-destructive, semidestructive, or destructive techniques. The main and foremost intention of disassembling these EOL products is to support the foremost goal of recovery process which is to minimize the natural resource depletion.

The cardinal quandary with the product recovery process is the uncertainty it poses, in regards to the components' quality. This dilemma is due to the lack of information regarding the condition of the components prior to them being disassembled. The blatantly clear solution is to test each individual component subsequent to their disassembly. However, product disassembly puts a financial burden on remanufacturer's profits, which, in turn, allays the profit margin of remanufacturing, which is requisite upon two factors: the monetary cost of conducting the appropriate and necessary testing of the entirety of the devices, and the sheer magnitude of obligatory time required to do so. What's more, if the test reveals the component is dysfunctional, it is a sort of assault on the manufacturer upon the realization that the totality of time spent attempting to process the EOL device(s), along with the resources that were required to do so were a waste of resources which could have been otherwise, efficiently utilized.

The quality of a remanufactured product induces hesitation for many people, in regards to its efficacy and reliability. Therefore, the consumers are unsure if remanufactured products will have the capacity to render the same expected performance as that of a new device. This uncertainty regarding a remanufactured product could lead the consumer to make a determination against its purchase. With such expansive consumer apprehension, remanufacturers often employ marketing strategies in attempts to provide affirmation about product durability. One stratagem that remanufacturers often employ to encourage customer security are product warranties (Murthy \& Blischke, 2006).

The use of sensor-embedded products (SEPs) is a promising approach in dealing with disassembly yield uncertainty. This is because SEPs utilize sensors implanted during the production process which work by monitoring the critical components of a product and facilitating data collection. The sensor accumulated data can aid in the prognosis of possible future product failures, as they provide an estimation of product component condition during the product's EOL stage. Moreover, the information gathered by sensors regarding any dysfunctional, replaced, or missing components prior to the disassembly of an EOL product contribute to important financial savings that would have otherwise been wasted in testing, disassembly, disposal, backorder, or holding costs processes (Ilgin \& Gupta, 2010a, 2010b).

This embedded in us the motivation to study and scrutinize the impact that would be had by offering renewing warranties containing the information retrieved by the sensor-embedded remanufactured products. We will analyze quantitatively the expansion achieved by using the SEP's information in several 
warranty analyses models depicting a remanufacturing line under various scenarios. Moreover, we will attempt to minimize the cost associated with warranty and to maximize the profit gained by remanufacturers by unearthing a warranty with an appealing price.

Because of the infinitely increasing levels of complexity and uncertainty associated with the remanufacturing process, the scope of this paper is limited to the following factors. EOL products and demanded components arrive at the remanufacturing facilities in accordance with the Poisson distribution. The disassembly and remanufacturing time exponentially assigned to each station are distributed accordingly. Imposing a cost for backorders will be calculated based on the duration of aforementioned backorder. Excessive and unessential EOL products and components are disposed of regularly according to a stringent disposal policy. A pull control production mechanism is used in all disassembly line settings contemplated and reviewed in this research study. Comparisons of warranty costs and temporal periods are made amongst different warranty policies.

The primary contribution offered by this paper is that it presents a quantitative assessment of the effect of offering warranties on remanufactured items from a remanufacturer's perspective in that it proposes an appealing price in the eyes of the buyer as well. While there are developmental studies on warranty policies for brand new products and a few on secondhand products, there exists no study that evaluates the potential benefits of warranties on remanufactured products in a quantitative and comprehensive manner. This paper studies and scrutinizes the impact of offering renewing warranties on remanufactured products. Specifically, the paper suggests a methodology which simultaneously minimizes the cost incurred by the remanufacturers and maximizes the confidence of the consumers towards buying remanufacturing products.

The rest of the paper is organized as follows: section 2 list all the related work from the literature review. System descriptions and design-of-experiment study are presented in Section 3 and Section 4 respectively. Section 5 presents the renewable one-dimensional warranty. Assumptions and notations are given in Section 6. Section 7 describes the preventive maintenance analysis. The failure analysis and warranty formulation are presented in Section 8 and Section 9 respectively. Finally, results and conclusions are given in Section 10. 


\section{Literature Review}

\subsection{Environmentally Conscious Manufacturing and Product Recovery}

In recent years, the number of studies dealing with environmentally conscious manufacturing and product recovery (ECMPRO) issues have gained gratuitous attention from researchers (Gungor \& Gupta 1999), (Ilgin, \& Gupta 2010b). This is partially due to environmental factors, government regulations, and public demands, but on the other side it is also due to economical profits obtained by implementing reverse logistics and product recycling resolutions. Manufacturers respond to consumer awareness of environmental issues and stricter environmental legislations by establishing designated facilities designed for the purpose of minimizing waste amassment by recovering materials and components derived from EOL products (Gungor \& Gupta 2002). Researchers have shed light on the panoptic environmentally conscious dilemmas involved in product manufacturing. As a result, researchers have released reviews of these panoptic issues involved in environmentally conscious manufacturing and product recovery (see for example, Moyer \& Gupta, 1997; Gungor \& Gupta, 1999; Ilgin \& Gupta, 2010c; Gupta, 2013; Ilgin, Gupta \& Battaïa, 2015). Disassembly is the most apex in the remanufacturing research area, which is due to its significant role in the all recovery system. For different aspects involved in disassembly, see the book by Lambert and Gupta (2005).

\subsection{Disassembly to Order Systems}

The objective of the disassembly to order systems (DTOs) is the determination of the optimal lot-sizes of EOL products to disassemble in order to satisfy the demand of various components from a mix of product types that have a number of components and/or modules in common (Gupta \& Lambert, 2008).

Kongar and Gupta (2002) proposed a single period integer Goal Programming (GP) model for a DTO system to determine the best combination of multiple products to selectively disassemble them to meet the demand for items and materials under a variety of physical, financial and environmental constraints and goals. Kongar and Gupta (2006) extended Kongar and Gupta (2002) study by using fuzzy GP to model the fuzzy aspiration levels of various goals. Langella (2007) developed a multi-period heuristic considering holding costs and external procurement of items. Gupta, Imtanavanich \& Nakashima (2009) used neural networks (NN) to solve the DTO problem. Kongar and Gupta (2009a) proposed a LPPbased solution methodology which can satisfy tangible or intangible financial, environmental and performance related measures of DTO systems. Kongar and Gupta (2009b) developed a multi-objective tabu search (TS) algorithm by considering multiple objective functions, viz. maximizing the total profit, 
maximizing the resale/recycling percentage, and minimizing the disposal percentage. Inderfurth and Langella (2006) developed two heuristic procedures (i.e., one-to-one, one-to-many) to investigate the effect of stochastic yields on the DTO system. Imtanavanich and Gupta (2006) use the heuristic procedures developed by Inderfurth and Langella (2006) to deal with the stochastic elements of the DTO system. Then, they useed a GP procedure to determine the number of returned products that satisfy various goals. Ondemir, Ilgin \& Gupta (2012) presented an Advanced Repair-to-Order and Disassembly-to-Order (ARTODTO) model. ARTODTO model deals with the products that are embedded with sensors and Radio-Frequency Identification (RFID) tags. The goal of the proposed model was to determine how to process each and every end-of-life product (EOLP) on hand to meet used product and component demands as well as recycled material demand. The model considered disassembly, repair, and recycling options for each EOLP in order to satisfy material and remaining-lifetime-based (sophisticated) component/product demands and minimize the total cost. Outside component procurement option was also assumed to be available. Ondemir and Gupta (2012) proposed a remanufacturing-to-order (RTO) system for end-of-life sensor embedded products (SEPs). An integer programming (IP) model was proposed to determine how to process each and every end-of-life product on hand to meet the quality-based product and component demands as well as recycled material demand while fulfilling the minimum cost objective. Ondemir and Gupta (2013) proposed an ARTODTO model for EOL processing of SEPs under demand and decision uncertainty. The proposed model was formulated as a fuzzy goal programming (FGP) model to achieve a variety of financial, environmental, and physical goals. Alqahtani, Gupta \& Nakashima (2014) extended Ondemir and Gupta (2013) study using simulation discrete model.

\subsection{Sensor Embedded Products}

Manufacturers are now able to build sensors in smaller sizes and at lower costs due to the expansion of technology. The use of sensor-based technologies on after-sale product condition monitoring is an active research area. Starting with the study of Scheidt and Shuqiang (1994), different methods of data acquisition from products during product usage were presented by the researchers (Karlsson, 1997, 1998; Klausner, Grimm \& Horvath, 1999; Petriu, Georganas, Petriu, Makrakis \& Groza, 2000; Simon, Bee, Moore, Pu \& Xie, 2001). Cheng, Huang, Chen and Hung (2004), developed a generic embedded device that could be installed in different types of equipment, including manufacturing equipment, portal servers, and automated, guided vehicles. This device has the ability of retrieving, collecting, and managing equipment data with the help of an embedded real-time operating system and several software modules. Yang, Moore, Pu and Wong (2009c) and Yang, Moore and Chong (2009b) developed an intelligent product model for discovering product service systems for consumer products, such as fridge/freezer 
appliances and game consoles for PlayStation2. In this model, an intelligent data unit was installed in each product to acquire data during usage and the distribution stages of its life cycle. The procurement of the essential life-cycle components of a product with sensors embedded in it is presented by Vadde, Kamarthi, Gupta and Zeid (2008). Additional studies aim to further explore whether or not the use of embedded sensors increases product life-cycle management effectiveness. A comprehensive survey on the commercial sensor systems used in health management for electronic products and systems was reported by Pecht (2008). Fang, Ong and Nee (2014), who investigated the modern practices leading toward the eventual development of embedded sensors in products in two primary categories, (viz., embedding sensors in products and representing and interpreting sensor data).

Another avenue of research hinges on the life cycle data analysis obtained via the implementation of various sensor-based data acquisition methods. In this scope, Mazhar, Kara and Kaebernick (2005) presented an integrated, two-stage approach which combined the Weibull analysis and multiple linear regression to assess the component reliability in refurbished products based on their life cycle data. Mazhar, Kara and Kaebernick (2007) carried out a similar analysis by integrating Weibull analysis with neural networks. Herzog, Marwala and Heyns (2009) compared the performance of several neural network variations in the prediction of the residual life of machines and components.

Although the majority of the studies presented above focus on the development of SEP models that enable product data acquisition during their life cycle and/or in their EOL phase, only a select few number of researchers have conferred a cost-benefit analysis. Klausner, Grimm and Hendrickson (1998a) analyzed the trade-off between the higher initial manufacturing costs caused by using an electronic data $\log (\mathrm{EDL})$ in products and the cost savings from the reuse of used motors. Simon et al. (2001) improved the cost-benefit analysis of Klausner, Grimm and Hendrickson (1998b) by taking into consideration the limited lifespan of a product's design. It was revealed that under certain circumstances, product servicing offers more readily reusable components in contrast to EOL recovery of parts.

\subsection{Warranty Analysis}

A warranty is a contractual obligation incurred by a manufacturer (vendor/seller) in connection with the sale of a product. The purpose of a warranty is to establish liability in the rare event that a purchased item fails prematurely or is unable to perform its intended function. These contracts specify the promised product performance and when this expected performance level is not met, a return of compensation is available to the buyer as compensation (Blischke, 1993). Product warranties have different main functions. One of the functions is insurance and protection, permitting buyers to transfer the risk of product failure back to the sellers (Heal, 1977). Secondly, 
product warranties can also signal product reliability to customers (Balachander, 2001; Gal-Or, 1989; Soberman, 2003; Spence, 1977), and lastly, the sellers can use warranties to extract additional profitability (Lutz \& Padmanabhan, 1995).

In contrast with massive literature on warranty policies for new items, up to now study on warranty policies for second-hand items receives less attention. Modelling the warranty cost analysis for used products is a novel field of research with a limited number of publications. The optimal upgrade strategies for second-hand items under both the virtual age along with the screening test reliability development methods are presented by Saidi-Mehrabad, Noorossana and Shafiee (2010), and Shafiee, Chukova, Yun and Akhavan-Niaki (2011a) who built a stochastic model designed to examine the optimal degree of investments for increasing the reliability of secondhand products under free repair warranty (FRW) policies. They concluded that a larger number of investments meant larger declines in the virtual age and greater reliability levels of the upgraded product. A stochastic reliability improvement model for used products with warranties and Cobb-Douglas-Type production function to reach the optimal upgrade level was presented by Shafiee, Finkelstein and Chukova (2011b). A study to determine the optimal upgrade, selling price and maximum expected profit with restrictive assumptions about the age distribution was conducted by Naini and Shafiee (2011). They built a mathematical model to implement a parametric analysis on the items' chronological ages to detect and determine the best policies. Yazdian, Shahanaghi and Makui (2014) adopted an integrated mathematical model that was not reliant on the specific age of the received item in order to determine the typically experienced remanufacturer decisions. The warranty policy and its effect on consumer behavior from the perspective of consumers has been studied by Liao, Li and Cheng (2015). A novel mathematicalstatistical model was proposed where decisions involving the pricing of returned used products (cores), with the degree of their remanufacturing, selling price, and warranty period for the final remanufactured products was to investigate the joint optimization of remanufacturing, pricing and warranty decision-making for end-of-life products (Yazdia et al., 2014). Kuik, Kaihara and Fujii (2015) presented mathematical models to examine two types of the proposed extended warranty policies for manufacturers so that they could make the comparisons of their possible gained profits of remanufactured products by the manufacturers who supplied them. In contrast, the analysis of warranty costs for remanufactured products has not yet received any significant attention. However, there are few papers that consider the warranty for the remanufactured products' reverse and closedloop supply chain management. Base and extended one-dimensional warranty can be offered for remanufacturing products using Free Replacement Warranty (FRW) and Pro-Rata Warranty (PRW) policy (Alqahtani \& Gupta, 2015a, 2015b, 2015c). Also, renewable, nonrenewable, one- and two-dimensional warranty policies can be offered for EOL derived products (Alqahtani \& Gupta, 2016a, 2016b, 2016c). 


\subsection{Maintenance Analysis}

Maintenance has a significant role in product reliability and quality. In the literature, maintenance is classified into two main types viz., corrective maintenance (CM) and preventive maintenance (PM). CM occurs when item fail and it performs to restore a failure item to an operational state; PM is performed before item fail in order to reduce degeneration and failure rate. In case of short product's remaining life, the warranty is also comparatively short and only CM actions are offered. Where in a product with long remaining life, warranty could be relatively long and warranty servicing costs can be reduced by carrying out PM actions. Thus, there is a relation between warranties, CM and PM.

The literature on maintenance policies is extensive. Several review papers on maintenance policies have appeared (Wang, 2002; Garg \& Deshmukh, 2006; Sharma, Yadava \& Deshmukh, 2011). We refer the reader to book by Nakagawa (2006) for the detailed information on the general area of maintenance theory. An extensive review of modelling maintenance policies can be found in book by Nakagawa (2008).

Maintenance policies for second-hand products during the warranty were not receiving researchers' interest. (Shafiee \& Chukova, 2013). Yeh, Lo and Yu (2011) proposed two periodical age reduction PM models to decrease the high failure rate of the second-hand products. Kim, Lim and Park (2011) studied the optimal periodic PM policies of a second-hand item following the expiration of warranty. From the manufacturer perspective, it is meaningful to carry out PM actions only when the saving of warranty servicing cost exceeds the additional cost occur by performing PM activities. Therefore, developing PM policies for remanufactured products still needs further researches (Alqahtani \& Gupta, 2017). 


\section{System Description}

This study used discrete-event simulation to optimize the implementation of a two-dimensional renewing warranty policy for remanufactured products. The implementation is illustrated using a specific product recovery system called the Advanced Remanufacturing-To-Order (ARTO) system. The experiments used in the study were designed using Taguchi's Orthogonal Arrays to represent the entire domain of the recovery system so as to observe the system behavior under various experimental conditions. In order to determine the optimum strategy offered by the remanufacturer, various warranty and preventive maintenance scenarios were analyzed using pairwise t-tests along with one-way analysis of variance (ANOVA) and Tukey pairwise comparisons tests for every scenario.

The Advanced Remanufacturing-To-Order (ARTO) system deliberated on in this study is a sort of product recovery system. A sensor embedded air conditioner (AC) is considered here as a product example. Based on the condition of EOL AC, it goes through a series of recovery operations as shown in Figure 1. Refurbishing and repairing processes may require reusable components in order to meet the demand of the product. This requirement satisfies both the internal and the external component demands. Thus, both will be satisfied using disassembly of recovered components. There are three different types of items arrivals in the ARTO system; either the EOL products for recovery process, failed SEP need to rectify or SEP due for maintenance activities. 


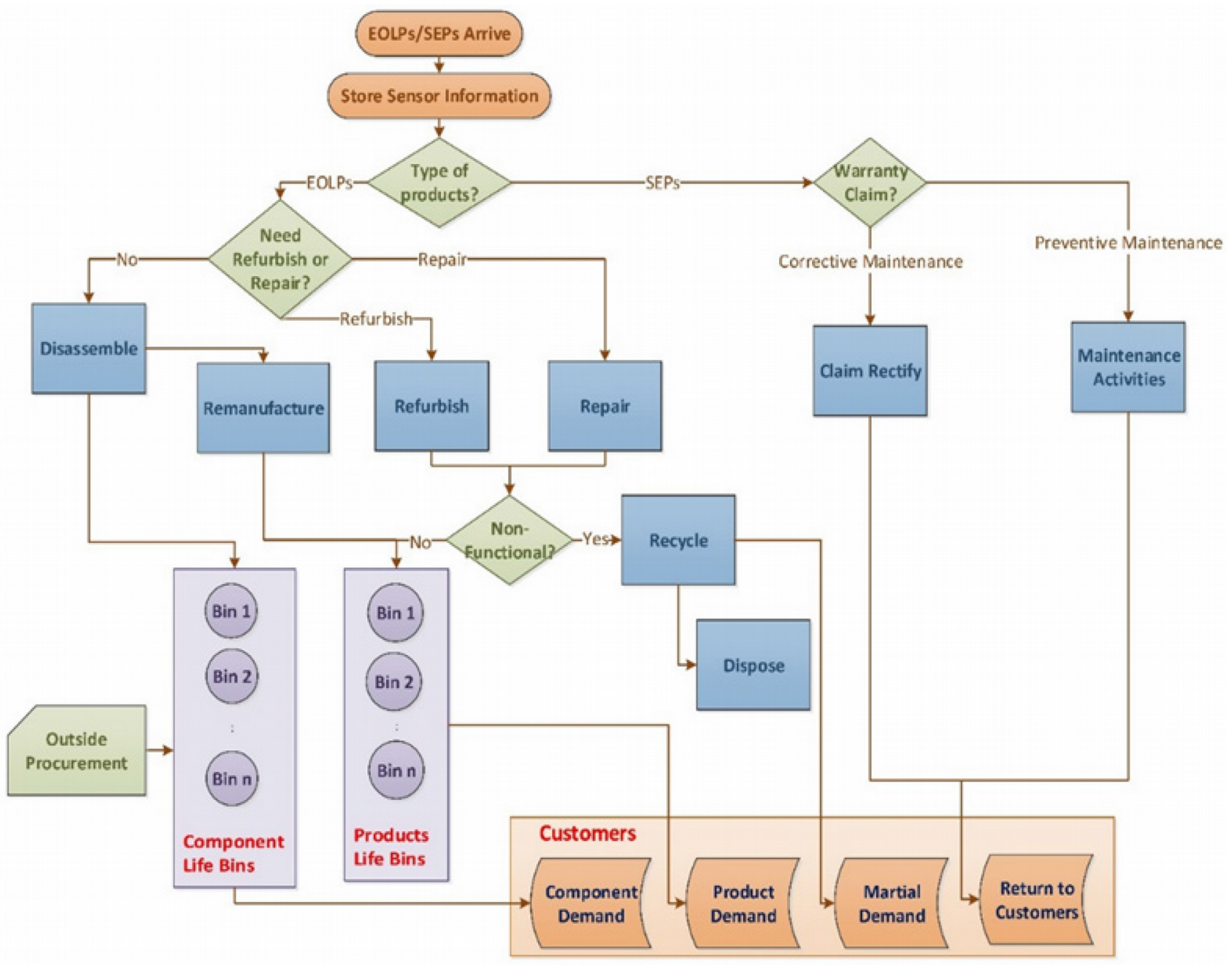

Figure 1. ARTO System's Recovery Processes

First, EOL ACs arrive at the ARTO system for information retrieval using a radio frequency data reader that is stored in the facility's database. Then the ACs go through a six-station disassembly line. Complete disassembly is performed for the purpose of extracting every single component. Table 1 represents the precedence of relationships between the AC components. There are nine components in an AC: the evaporator, control box, blower, air guide, motor, condenser, fan, protector, and compressor. Exponential distributions are used to generate the station disassembly times, interarrival times of each component's demand, and interarrival times of EOL AC. All EOLPs after retrieval of the information are shipped either to station 1 for disassembly or, if EOLP only needs a repair for a specific component, it is instead sent to its corresponding station. Two different types of disassembly operations, viz., destructive or nondestructive, are used depending on the component's condition. If the disassembled component is not functional (broken, zero percent of remaining life), then destructive disassembly is utilized in such a way that the other components' functionality is not damaged. Therefore, unit disassembly cost for a functional component is higher than for a nonfunctional component. After disassembly, there is no need for component testing due to the availability of 
information regarding components' conditions from their sensors. It is assumed that the demands and life cycle information for EOLPs are known. It is also assumed that the retrieval of information from sensors costs less than the actual inspecting and testing.

\begin{tabular}{|c|r|c|c|}
\hline Component name & Station & Code & Preceding component \\
\hline Evaporator & 1 & A & - \\
\hline Control box & 2 & B & A, B \\
\hline Blower & 3 & C & A, B, C \\
\hline Air guide & 4 & D & A, B, C, D \\
\hline Motor & 5 & F & - \\
\hline Condenser & 5 & G & F \\
\hline Fan & 6 & H & H \\
\hline Protector & 6 & I & \\
\hline Compressor & & & E \\
\hline
\end{tabular}

Table 1. AC Components and precedence relationship

Recovery operations differ for each SEP based on their overall condition and estimated remaining life. Recovered components are used to meet spare parts demands, while recovered or refurbished products are used for consumer product demands. Also, material demands are met using recycled products and components. Recovered products and components are characterized based on their remaining lifespans and are placed in different life-bins (e.g. one year, two years, etc.) where they wait to be retrieved via a customer demand. Underutilization of any product or component can happen when it is qualified for a higher life-bin but is placed in a lower life-bin because the higher life-bin is full. Any product, component, or material inventory that is greater than the maximum inventory allowed is assumed to be of excess and is instead used for material demand or is simply disposed of.

In order to meet the product demand, repair and refurbish options could also be chosen as presented in Figure 2. EOLP may have missing or nonfunctional (broken, zero remaining life) components that need to be replaced or replenished during the repairing or refurbishing process in order to meet certain remaining life requirements. EOLP may also consist of components having lesser remaining lives than desired, and, for that reason, might also have to be replaced. 


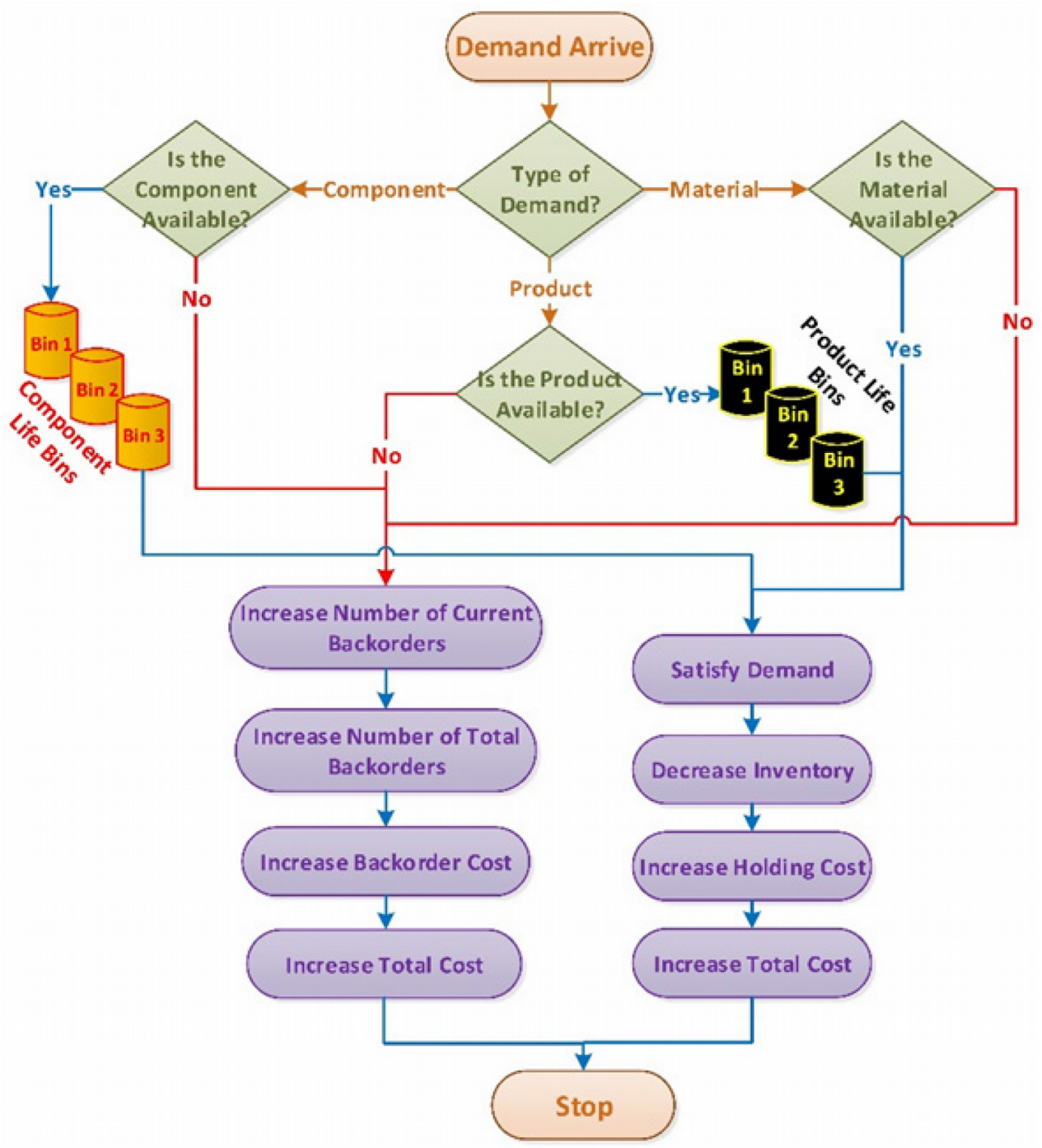

Figure 2. ARTO System Demand Process

In case of failure SEP during warranty period, The failed ACs arrive at the ARTO system for information retrieval using a radio frequency data reader that is stored in the facility's database. Then the failure ACs goes through the recovery operations explain before same as an EOLP.

Finally, in order to reduce the risk of failure, PM actions are carried out during the warranty period. Here, if the remaining life of a remanufactured AC reaches a pre-specified value the remanufactured SEPs arrive at the ARTO system for information retrieval using a radio frequency data reader that is stored in the facility's database. Then, the SEPs go through four maintenance activities based on the information from the sensor about their condition. These maintenance activities include measurements, adjustments, parts replacement, and cleaning. When PM actions are performed with degree $\delta$, the remaining life of the remanufactured ACs will be $\delta$ units of time more than before as shown in Figure 3. Meanwhile, any failures between two successive PM actions during warranty period are rectified at no cost to the customer 


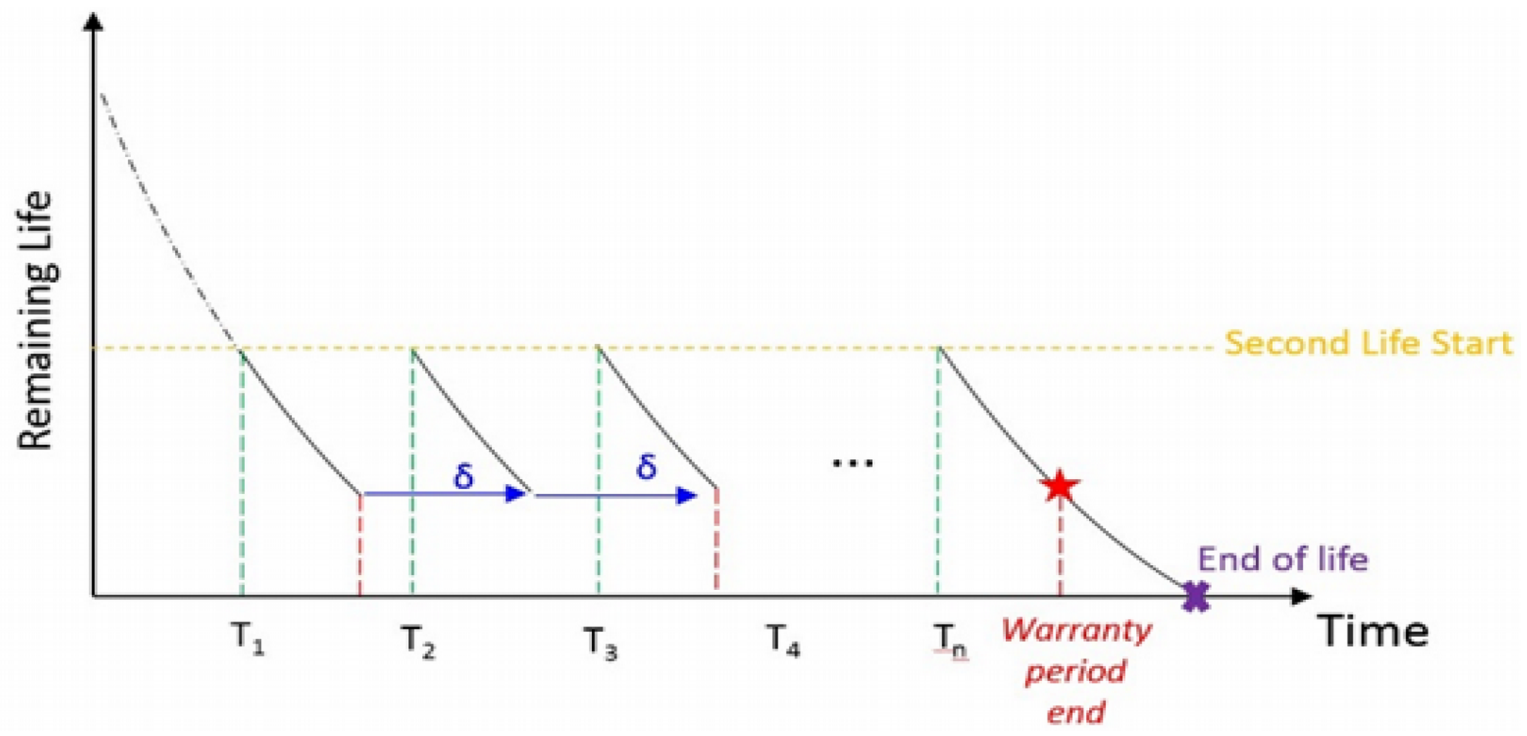

Figure 3. Scheme for PM policies for remanufactured Products

\section{Design-of-Experiments Study}

According to a comprehensive study for the quantitative evaluation of the SEPs on the performance of a disassembly line conducted by Ilgin and Gupta (2011), it was show that smart SEPs are a favorable resolution in handling remanufacturing customer uncertainty. To test this claim on ARTO, we built a simulation model to represent the full recovery system and observed its behavior under different experimental conditions. ARENA program, Version 14.5, was used to build the discrete-event simulation models. A three-level factorial design was used with 51 factors that were considered each at 3 levels. These were identified as low, intermediate, or high levels. The reason that the three-level designs were proposed was to model possible curvature in the response function and to handle the case of nominal factors occurring at 3 levels. The parameters, factors, and factor levels are given in Table 2 and Table 3. A full-factorial design with 54 factors at 3 levels requires an extensive number of experiments (viz., $5.815 \mathrm{E}+25)$. To reduce the number of experiments to a practical level, a small set of all the possible combinations was picked. The selection method of an experiment's number is called a partial fraction experiment, which yields the most information possible of all the factors that affect the performance parameter with minimum number of experiments possible. For these types of experiments, Taguchi (1986), enacted specific guidelines. A new method of conducting the experimental design was to use a special set of arrays called orthogonal arrays (OAs) that were built by Taguchi. Orthogonal arrays provided a way to only have to conduct a minimal number of experiments. In most cases, orthogonal array is more efficient when compared to many other statistical designs. The minimum number of experiments that are required to conduct the Taguchi method can be calculated based on the degrees of freedom approach. 


\begin{tabular}{|c|c|c|c|c|c|}
\hline Parameters & Unit & Value & Parameters & Unit & Value \\
\hline Backorder cost rate & $\%$ & 40 & Price for 3 Years Air Guide & $\$$ & 15 \\
\hline Holding cost rate & $\$ /$ hour & 10 & Price for 3 Years Motor & $\$$ & 60 \\
\hline Remanufacturing cost & $\$$ & 1.5 & Price for 3 Years Condenser & $\$$ & 25 \\
\hline Disassembly cost per minute & $\$$ & 1 & Price for 3 Years Fan & $\$$ & 20 \\
\hline Price for 1 Year Evaporator & $\$$ & 10 & Price for 3 Years Protector & $\$$ & 20 \\
\hline Price for 1 Year Control Box & $\$$ & 20 & Price for 3 Years Compressor & $\$$ & 65 \\
\hline Price for 1 Year Blower & $\$$ & 5 & Weight for Evaporator & lbs. & 8 \\
\hline Price for 1 Year Air Guide & $\$$ & 5 & Weight for Control Box & lbs. & 4 \\
\hline Price for 1 Year Motor & $\$$ & 45 & Weight for Blower & lbs. & 2 \\
\hline Price for 1 Year Condenser & $\$$ & 15 & Weight for Air Guide & lbs. & 2 \\
\hline Price for 1 Year Fan & $\$$ & 15 & Weight for Motor & lbs. & 6 \\
\hline Price for 1 Year Protector & $\$$ & 15 & Weight for Condenser & lbs. & 12 \\
\hline Price for 1 Year Compressor & $\$$ & 50 & Weight for Fan & lbs. & 3 \\
\hline Price for 2 Years Evaporator & $\$$ & 15 & Weight for Protector & lbs. & 3 \\
\hline Price for 2 Years Control Box & $\$$ & 30 & Weight for Compressor & lbs. & 6 \\
\hline Price for 2 Years Blower & $\$$ & 12 & Unit copper scrap revenue & $\$ / \mathrm{lbs}$ & 0.6 \\
\hline Price for 2 Years Air Guide & $\$$ & 12 & Unit Fiberglass scrap revenue & $\$ / \mathrm{lbs}$ & 0.9 \\
\hline Price for 2 Years Motor & $\$$ & 55 & Unit steel scrap revenue & $\$ / \mathrm{lbs}$ & 0.2 \\
\hline Price for 2 Years Condenser & $\$$ & 18 & Unit disposal cost & $\$ / \mathrm{lbs}$ & 0.3 \\
\hline Price for 2 Years Fan & $\$$ & 18 & Unit copper scrap Cost & $\$ / \mathrm{lbs}$ & 0.3 \\
\hline Price for 2 Years Protector & $\$$ & 20 & Unit Fiberglass Scrap Cost & $\$ / \mathrm{lbs}$ & 0.45 \\
\hline Price for 2 Years Compressor & $\$$ & 60 & Unit steel scrap Cost & $\$ / \mathrm{lbs}$ & 0.1 \\
\hline Price for 3 Years Evaporator & $\$$ & 20 & Price of 1 Year AC & $\$$ & 180 \\
\hline Price for 3 Years Control Box & $\$$ & 35 & Price of 2 Years AC & $\$$ & 240 \\
\hline Price for 3 Years Blower & $\$$ & 15 & Price of 3 Years AC & $\$$ & 275 \\
\hline Operation costs for Evaporator & $\$$ & 4 & Operation costs for Condenser & $\$$ & 1.66 \\
\hline Operation costs for Control Box & $\$$ & 4 & Operation costs for Fan & $\$$ & 2.34 \\
\hline Operation costs for Blower & $\$$ & 2.8 & Operation costs for Protector & $\$$ & 0.6 \\
\hline Operation costs for Air Guide & $\$$ & 1.2 & Operation costs for Compressor & $\$$ & 3.4 \\
\hline Operation costs for Motor & $\$$ & 4 & Operation costs for $\mathrm{AC}$ & $\$$ & 55 \\
\hline
\end{tabular}

Table 2. Parameters used in the ARTO system 


\begin{tabular}{|c|c|c|c|c|c|}
\hline \multirow[b]{2}{*}{ No } & \multirow[b]{2}{*}{ Factor } & \multirow[b]{2}{*}{ Unit } & \multicolumn{3}{|c|}{ Levels } \\
\hline & & & 1 & 2 & 3 \\
\hline 1 & Mean arrival rate of EOL ACs & Products/hour & 10 & 20 & 30 \\
\hline 2 & Probability of Repair EOLPs & $\%$ & 5 & 10 & 15 \\
\hline 3 & Probability of a nonfunctional control box & $\%$ & 10 & 20 & 30 \\
\hline 4 & Probability of a nonfunctional motor & $\%$ & 10 & 20 & 30 \\
\hline 5 & Probability of a nonfunctional fan & $\%$ & 10 & 20 & 30 \\
\hline 6 & Probability of a nonfunctional compressor & $\%$ & 10 & 20 & 30 \\
\hline 7 & Probability of a missing control box & $\%$ & 5 & 10 & 15 \\
\hline 8 & Probability of a missing motor & $\%$ & 5 & 10 & 15 \\
\hline 9 & Probability of a missing fan & $\%$ & 5 & 10 & 15 \\
\hline 10 & Probability of a missing compressor & $\%$ & 5 & 10 & 15 \\
\hline 11 & Mean non-destructive disassembly time for station 1 & Minutes & 1 & 1 & 1 \\
\hline 12 & Mean non-destructive disassembly time for station 2 & Minutes & 1 & 1 & 1 \\
\hline 13 & Mean non-destructive disassembly time for station 3 & Minutes & 1 & 1 & 1 \\
\hline 14 & Mean non-destructive disassembly time for station 4 & Minutes & 1 & 1 & 1 \\
\hline 15 & Mean non-destructive disassembly time for station 5 & Minutes & 1 & 1 & 1 \\
\hline 16 & Mean non-destructive disassembly time for station 6 & Minutes & 1 & 2 & 2 \\
\hline 17 & Mean destructive disassembly time for station 1 & Minutes & 0 & 1 & 1 \\
\hline 18 & Mean destructive disassembly time for station 2 & Minutes & 0 & 1 & 1 \\
\hline 19 & Mean destructive disassembly time for station 3 & Minutes & 0 & 1 & 1 \\
\hline 20 & Mean destructive disassembly time for station 4 & Minutes & 0 & 1 & 1 \\
\hline 21 & Mean destructive disassembly time for station 5 & Minutes & 0 & 1 & 1 \\
\hline 22 & Mean destructive disassembly time for station 6 & Minutes & 1 & 1 & 1 \\
\hline 23 & Mean Assembly time for station 1 & Minutes & 1 & 1 & 2 \\
\hline 24 & Mean Assembly time for station 2 & Minutes & 1 & 1 & 2 \\
\hline 25 & Mean Assembly time for station 3 & Minutes & 1 & 1 & 2 \\
\hline 26 & Mean Assembly time for station 4 & Minutes & 1 & 1 & 1 \\
\hline 27 & Mean Assembly time for station 5 & Minutes & 1 & 1 & 2 \\
\hline 28 & Mean Assembly time for station 6 & Minutes & 1 & 2 & 2 \\
\hline 29 & Mean demand rate Evaporator & Parts/hour & 10 & 15 & 20 \\
\hline 30 & Mean demand rate for Control Box & Parts/hour & 10 & 15 & 20 \\
\hline 31 & Mean demand rate for Blower & Parts/hour & 10 & 15 & 20 \\
\hline 32 & Mean demand rate for Air Guide & Parts/hour & 10 & 15 & 20 \\
\hline 33 & Mean demand rate for Motor & Parts/hour & 10 & 15 & 20 \\
\hline 34 & Mean demand rate for Condenser & Parts/hour & 10 & 15 & 20 \\
\hline 35 & Mean demand rate for Fan & Parts/hour & 10 & 15 & 20 \\
\hline 36 & Mean demand rate for Protector & Parts/hour & 10 & 15 & 20 \\
\hline 37 & Mean demand rate for Compressor & Parts/hour & 10 & 12 & 20 \\
\hline 38 & Mean demand rate for 1 Year AC & Products/hour & 5 & 10 & 15 \\
\hline 39 & Mean demand rate for 2 Years AC & Products/hour & 5 & 10 & 15 \\
\hline 40 & Mean demand rate for 3 Years AC & Products/hour & 5 & 10 & 15 \\
\hline
\end{tabular}




\begin{tabular}{|c|c|c|c|c|c|}
\hline \multirow[b]{2}{*}{ No } & \multirow[b]{2}{*}{ Factor } & \multirow[b]{2}{*}{ Unit } & \multicolumn{3}{|c|}{ Levels } \\
\hline & & & 1 & 2 & 3 \\
\hline 41 & Mean demand rate for Refurbished AC & Products/hour & 5 & 10 & 15 \\
\hline 42 & Mean demand rate for Material & Products/hour & 5 & 10 & 15 \\
\hline 43 & Percentage of Good Parts to Recycling & $\%$ & 95 & 90 & 80 \\
\hline 44 & Mean Metals Separation Process & Hour & 1 & 1 & 2 \\
\hline 45 & Mean Copper Recycle Process & Minutes & 1 & 1 & 2 \\
\hline 46 & Mean Steel Recycle Process & Minutes & 1 & 1 & 2 \\
\hline 47 & Mean Fiberglass Recycle Process & Minutes & 1 & 1 & 2 \\
\hline 48 & Mean Dispose Process & Minutes & 1 & 1 & 1 \\
\hline 49 & Maximum inventory level for AC & Products/hour & 10 & 15 & 20 \\
\hline 50 & Maximum inventory level for Refurbished AC & Products/hour & 10 & 15 & 20 \\
\hline 51 & Maximum inventory level for AC Component & Products/hour & 10 & 15 & 20 \\
\hline 52 & Level of Preventive Maintenance effort & - & 0.5 & 0.6 & 0.7 \\
\hline 53 & Number of Preventive Maintenance to perform & \# & 2 & 3 & 4 \\
\hline 54 & Time between each Preventive Maintenance & Months & 1 & 2 & 3 \\
\hline
\end{tabular}

Table 3. Factors and factor levels used in design-of-experiments study

So, the number of experiments must be greater than or equal to a system's degrees-of-freedom. The Precisely, $\mathrm{L}_{109}\left(3^{54}\right)$ (i.e., $109=[($ Number of levels -1$) \mathrm{x}$ Number of Factors $\left.]+1\right)$ Orthogonal Arrays were chosen because the degree of freedom ARTO system is 101, meaning it requires 101 experiments to accommodate 54 factors upon three different levels. Additionally, orthogonal array assumes that there is no interaction between any two factors.

Furthermore, for validation and verification purposes animations of the simulation models were built along with multiple dynamic and counters plots. 2,000 replications with six months (eight hours a shift, one shifts a day and 5 days a week) were used to run each experiment. Arena models calculate the profit using the following equation:

\section{Profit $=$ SR + CR + SCR-HC-BC-DC-DPC-TC-RMC-TPC-PMC-WC}

where $S R$ is the total revenue generated by the product; component and material sales during the simulated run time; $C R$ is the total revenue generated by the collection of EOL ACs during the simulated run time; $S C R$ is the total revenue generated by selling scrap components during the simulated run time; $H C$ is the total holding cost of products, components, material and EOL ACs during the simulated run time; $B C$ is the total backorder cost of products, components and material during the simulated run time; $D C$ is the total disassembly cost during the simulated run time; DPC is the total disposal cost of components, material and EOL ACs during the simulated run time. TC is the total testing cost during the 
simulated run time; $R M C$ is the total remanufacturing cost of products during the simulated run time; TPC is the total transportation cost during the simulated run time; PMC is the total preventive maintenance cost during the simulated run time and $W C$ is the total warranty cost.

In each EOL AC, there are three types of scraps that need to be recovered and sold. The evaporator and condenser are sold as copper scrap, Chassis and metal covers are sold as steel scraps and blowers, fan and air guides are sold as fiberglass. All the other components are considered to be waste components. Scrap revenue from steel, copper, and fiberglass components is calculated by multiplying their weight in pounds by the units of scrap revenue produced by each metal type. Disposal cost is calculated as well by multiplying the waste weight by the unit disposal cost. The time of retrieving information from smart sensors is assumed to be 20 seconds per AC. The transportation cost is assumed to be $\$ 50$ for each trip taken by the truck. There are different prices in the secondary market of recovery product due to different level of quality.

\section{Renewable Two-Dimensional Warranty}

During the process of deciding to purchase a product, the buyer usually compare features of a product with other competing brands that are selling the same product. In some cases, the competing brands produce similar products bearing similar features such as the costs, special characteristics, quality, credibility of the product, and even insurance from the provider. In these cases, after sale factors come into effect, such as the discount, warranty, availability of parts, repairs, and other services. These factors will be very significant to the buyer in such a situation. So will the warranty since it further assures the buyer of the reliability of the product.

A warranty is an agreement that requires the manufacturer to correct any product failures or to compensate the buyer for any problems that may occur with the product during the warranty period in relevance to its sale. The objective of the warranty is to promote the product's quality and guarantee its performance in order to assure productivity for both the manufacturer and the buyer. For a given product, the warranty cost (in a statistical sense) is the same for all new items if the manufacturer has good quality control. In contrast, each EOL product is different due to factors such as age, usage, and maintenance history. This makes the warranty cost for each remanufactured product derived from an EOL item statistically different.

The importance of warranties for remanufactured products is increasing because consumers are becoming more demanding of product quality and the increase in customer's awareness of the environment will increase the demand for remanufactured products and future costs of 
replacement/repair in case of product failures. Therefore, warranty management has become very important to remanufacturers of remanufactured products. They need to estimate the warranty cost in order to factor it into the pricing structure. Failure to do so can result in the remanufacturers incurring loss, as opposed to profit, with the sale of remanufactured items. Analyses of warranty costs for remanufactured products are more complex when compared to new products because of the uncertainties in usage and maintenance history. Moreover, warranty policies similar to new and secondhand products may not be economically acceptable from the remanufacturer's point of view. Therefore, there is a need to test and compare these warranty policies for remanufactured products and estimate the expected warranty cost associated with these policies. There are other related issues such as the servicing strategies involving remanufactured spare parts in the replacement/repair of failures during the warranty period.

In the two-dimensional warranty, a policy is defined by a region in a two-dimensional plane, typically with one axis representing time or age and the other axis representing the usage. For renewing policies, the warranty period begins anew with each replacement or repair. Therefore, the warranty period is uncertain as the warranty expires only when an item does not fail for a period W, as shown in Figure 4. There are many different available two-dimensional consumer warranty policies which most products are sold with. The most famous renewing consumer warranties are the Renewing Free Replacement Warranty (FRW) and Renewing Pro-Rata Warranty (PRW), or a combination of the both FRW/PRW.

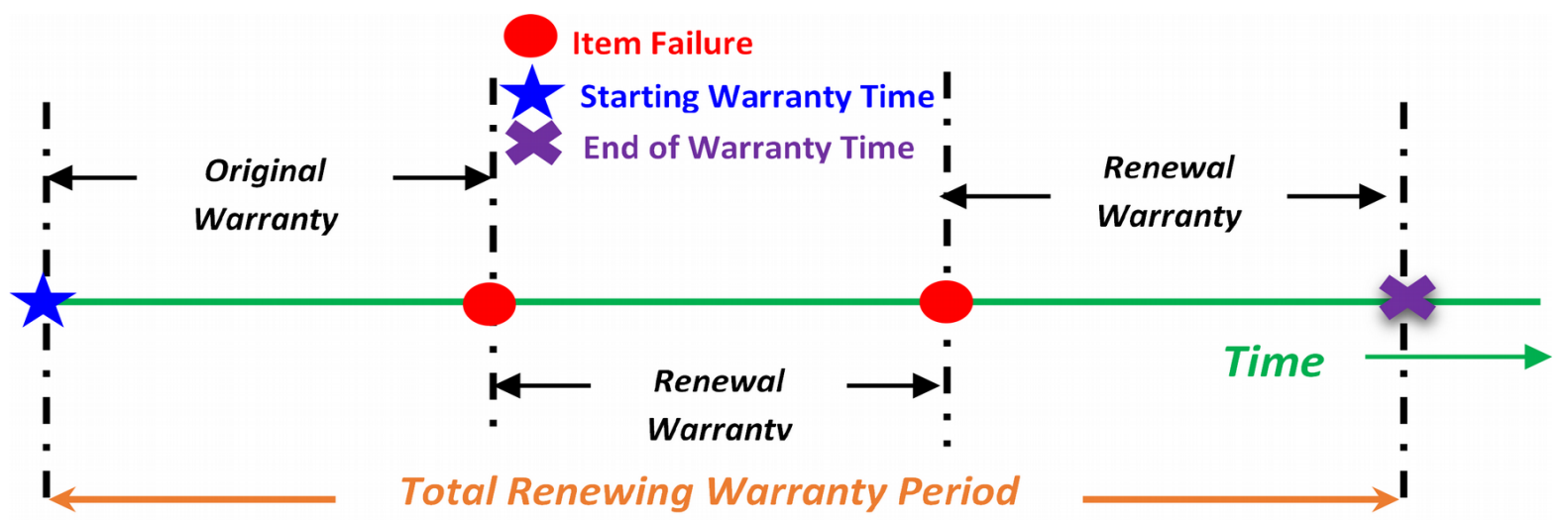

Figure 4. Parameters used in the ARTO system 


\section{Assumptions and Notations}

This section starts with the model assumptions. Then, the notation of all the parameters used in this paper.

\subsection{Assumptions}

The following assumptions have been considered to simplify the analysis:

i. The failures are statistically independent.

ii. Every item failure under warranty period results in a claim.

iii. All claims are valid.

iv. The failure of a remanufactured item is only a function of its age.

v. The time to carry out the replacement/repair action is relatively small compared to the mean time between failures.

vi. The cost to service warranty claim (for repair/replacement of failed components) is a random variable.

\subsection{Notations}

$W: \quad$ Warranty period;

$W_{\mathrm{i}}: \quad$ Limits of warranty period;

U: Warranty usage;

$U_{\mathrm{i}}: \quad$ Limits of warranty usage;

$\Omega: \quad$ Warranty region;

$\Omega_{i} \quad$ Warranty sub-region $i$;

$C_{0}: \quad$ Operating cost of item;

Cs: $\quad$ Sale price of item;

$C_{p}: \quad$ Cost of remanufacturing a remanufactured item;

$n: \quad$ Number of components in a remanufactured item;

RL: $\quad$ Remaining life of remanufactured item at sale; 
RLi: $\quad$ Remaining life of component $i(1 \leq i \leq n)$;

$j: \quad$ Number of preventive maintenance;

$v: \quad$ Virtual remaining life;

$v_{j}$ : $\quad$ Virtual remaining life after performing the $f^{\text {th }}$ PM activity;

m: $\quad$ Level of PM effort;

$\delta(m)$ : Remaining life increment factor of PM with effort m;

$t: \quad$ Remaining life of remanufactured item at failure;

$x: \quad$ Usage of remanufactured item at failure;

$\Lambda(R L):$ Intensity function for system failure;

$F_{i}($.$) : Marginal distribution function of F(.,$.$) ;$

$F(.,$.$) : Bivariate distribution function;$

$F(. \mid$.$) : Conditional distribution function;$

$R(.,$.$) : Refund function for two-dimensional warranty;$

$N($. ): Number of replacements under warranty;

$N(.,$.$) : Tow-Dimensional renewal function associated with F(.,$.$) ;$

$N(W ; R L): \quad$ Number of failures over the warranty period with remaining life, $R L$;

$\tau_{r i}: \quad$ Time at which warranty expires;

$G($.$) Distribution function of usage rate;$

E[.]: $\quad$ Expected value of expression within [.];

$C_{d}(W ; R L):$ Total warranty cost to remanufacturer;

\section{Preventive Maintenance Analysis}

Usually, a PM activities involve a set of maintenance tasks, such as, cleaning, systematic inspection, lubricating, adjusting and calibrating, replacing different components, etc. (Ben-Mabrouk, Chelbi \& Radhoui, 2016). The right PM activities can be able to reduce the number of failures efficiently, as a result reduce the warranty cost and increased the customer satisfaction. This study, adopt the modelling framework proposed by Kim, Djamaludin and Murthy (2004) to model the effect of PM activities. 
A series of PM activities of a remanufactured item are performed at remaining life $R L_{1}, R L_{2}, \ldots R L_{j}, \ldots$, with $R L_{0}=0$. Here, the effect of PM results in a restoration of the item so that the item's virtual remaining life is effectively increase. The concept of virtual age is introduced in Kijima, Morimura and Suzuki, 1988; and then extended in Kijima (1989). In this study, the $j^{\text {th }}$ PM only reimburses the damage accrued during the time between the $(j-1)^{\text {th }}$ and the $j^{\text {th }} \mathrm{PM}$ activities, as a result an arithmetic reduction of virtual remaining life can be obtain (Martorell, Sanchez \& Serradell 1999). Therefore, the virtual remaining life after performing the $j^{\text {th }}$ PM activity, i.e. $R L_{j}$, is then given by

$$
v_{j}=v_{j-1}+\delta(m)\left(R L_{j}-R L_{j-1}\right)
$$

where $\mathrm{m}$ is the level of PM effort, and $\delta(m), m=0,1, \ldots, M$, is the remaining life increment factor of PM with effort $\mathrm{m}$. Note that, the effect of PM depends on its level $m, 0 \leq m \leq M$, and its relationship with the remaining life is characterized by the age-incremental factor $\delta(m)$. Larger value of $\mathrm{m}$ represents greater PM effort, hence $\delta(m)$ is a increasing function of $\mathrm{m}$ with $\delta(0)=0$ and $\delta(M)=1$. More specifically, if $m=$ 0 , then $v_{j}=R L_{j}, \mathrm{j} \geq 1$, which means that the item is restored to as bad as old (ABAO); if $m=M$, the item is restored back to as good as new (AGAN); while in a more general case $m \in(0, M)$, the item is partially restored, i.e. the PM activity is imperfect. This concept will be used in the next section to derive the expected.

\section{Failures and Renewal Process}

Most products are complex and multipart so that an item can be viewed as a system consisting of several components. The failure of an item occurs due to the failure of one or more components. A remanufactured products or component is categorized in terms of two states viz., working or failed. The time intervals between consecutive failures are random variables and modelled by proper distribution functions. Interchangeably, the number of failures over time can model by a suitable counting process.

The actions to make a failed item operational depend on whether the failed component(s) are repairable or not. In the case of a repairable component, the remanufacturer has the option of repairing or replacing it by a remanufactured working component if available. If not a new component will be used to rectify the claim. In case of repairable components, the characterization of subsequent failures depends on the type of repair (e.g., minimal repair, imperfect repair and so on). Similarly, in the case of a non-repairable component, the remanufacturer can use a remanufactured working component in the replacement to make the item operational. 
In two-dimensional warranty policies, remanufactured item failures can be viewed as random points occurring over a two-dimensional region. Time to first failure of a remanufactured component depends on the mean remaining lifetime (MRL) and the PM of the component at the time of sale of the remanufactured product. If the sensor information about EOL component indicates that it has never failed, or was always minimally repaired, then the remaining life of the component at sale is the same as that of the item. Usually, the MRL of remanufactured component at sale differs due to the replacement or repair and maintenance actions. Therefore, the time to first failure under warranty needs to be defined. Let $R L_{i}$ denote the remaining life of remanufactured component, $i$. There are two cases: either $R L_{i}$ is known because of embedded sensor or $R L_{i}$ is unknown because it is a conventional product.

The sensor embedded in the item provides the remanufacturer with the MRL of the item at sale and the virtual remaining life due to upgrades and maintenances information. The item failure is modelled by a point process with intensity function $\Lambda(R L)$ where $R L$ represents the remaining life of the item. $\Lambda(R L)$ is a decreasing function of $R L$ indicating that the number of failures increases with remaining life decrease. The failures over the warranty period occur according to a non-stationary Poisson process with intensity function $\Lambda(\mathrm{RL})$. This implies that $\mathrm{N}$ (W; RL), the number of failures over the warranty period $W$ for an item of remaining life $R L$ at the time of sale and virtual remaining life $v$, is a random variable with

$$
P\{N(W ; R L)=n\}=\left\{\int_{v}^{v+W} \Lambda(R L) d R L\right\} \mathrm{e}^{-\int_{v}^{v+W} \Lambda(R L) d R L} / n !
$$

The expected number of failures over the warranty period is given by

$$
E[N(W ; R L)]=\int_{v}^{v+W} A(R L) d R L
$$

The expected number of renewals over the warranty period is given by the two-dimensional renewal function

$$
N(t, x)=F(t, x)+\int_{0}^{x} \int_{0}^{t} N(t, x) d F(t, x)
$$

ARENA 14.5 is used to generate the remaining life and usage of remanufactured item at failure; (ti, $x i)$, using a bivariate random number generator and time history of replacements under warranty and repeat sales over the simulation time interval. The ARENA simulation program yields the remaining life and usage at failures under warranty; the virtual remaining life after preventive maintenance activities, the number of replacements under warranty for each purchase and the time between repeat purchases. 


\section{Warranty Formulation}

\subsection{Renewing 2D Free Replacement Warranty Policy}

Under this policy whenever a remanufactured item fails in the warranty region; $\Omega$, the remanufacturer replaced all failures with a remanufactured one at no cost to the buyer. The replacement comes with a new warranty identical to the original one. There are four different warranty regions under FRW policy as shown in Figure 5.

(a)

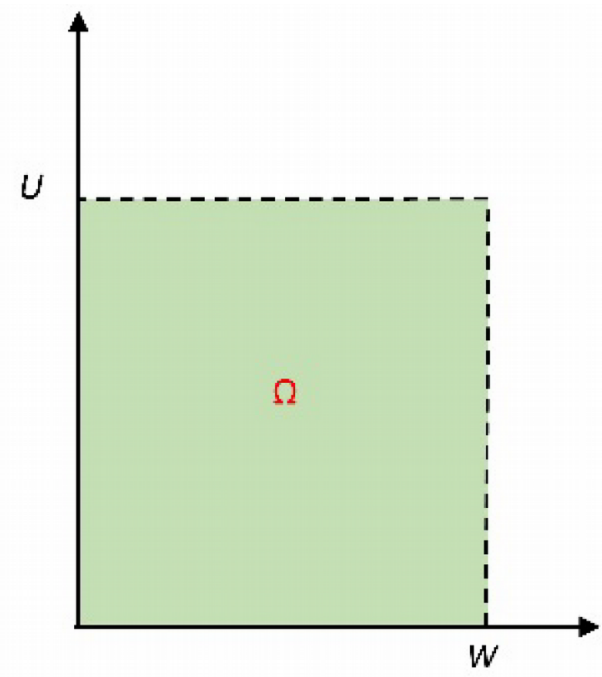

(c)

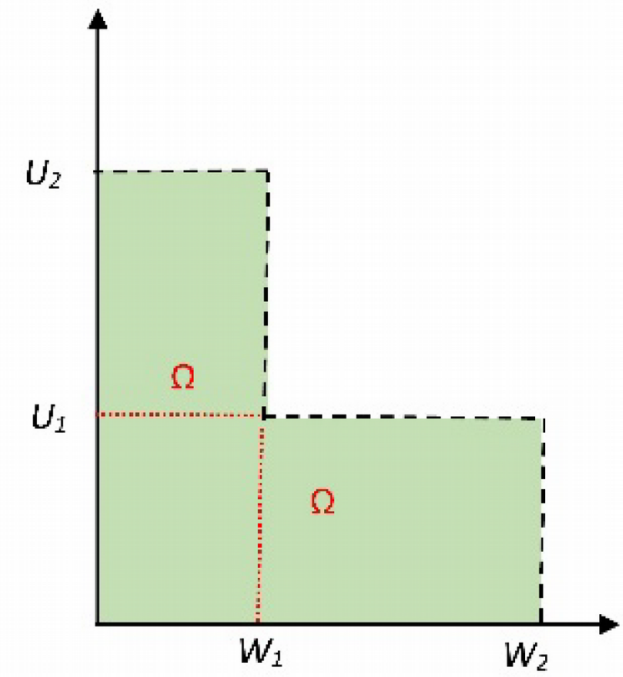

(b)

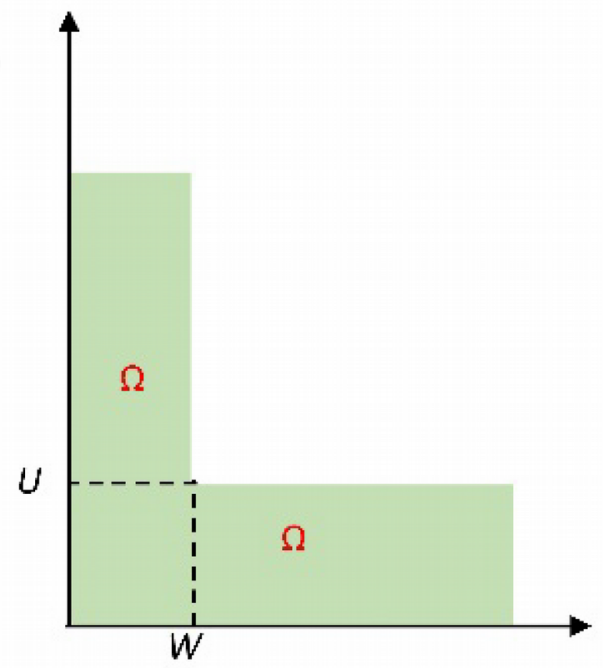

(d)

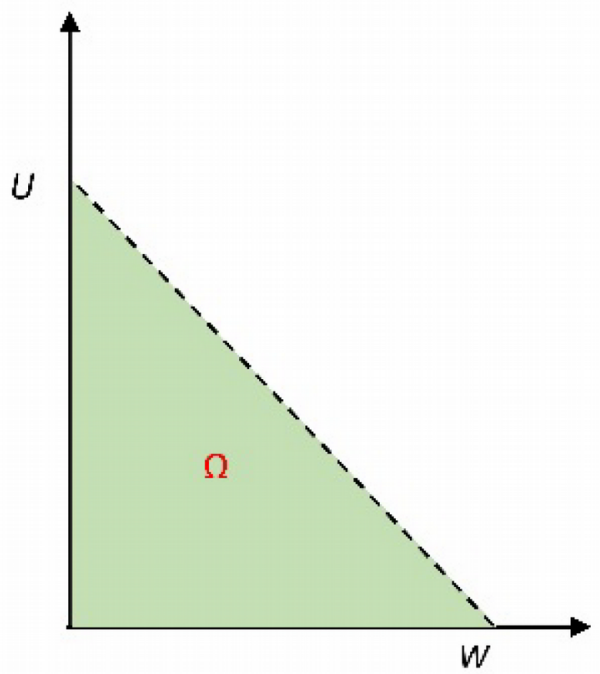

Figure 5. Warranty Regions for Renewing FRW 


\subsubsection{Renewing FRW with Rectangle Region}

The warranty region is characterized by a rectangle shape as shown in Figure 5(a). The warranty expires the first time a failure occurs outside the rectangle. The policy assures the buyer a maximum cover for $W$ unit of time and/or $U$ unit of usage. As a result the number of replacements under warranty, $N(R L)$, is a random variable distributed according to a geometric distribution function with $E[N(R L)]$ given by

$$
E[N(R L)]=\frac{1}{1-F(W, U)}
$$

The expected warranty cost per remanufactured item is given by

$$
E\left[C_{d}(W ; R L)\right]=\frac{C_{s}(R L)}{1-F(W, U)}
$$

\subsubsection{Renewing FRW with Infinite Strips Region}

The warranty region is characterized by two infinite dimensional strips as shown in Figure 5(b). Under this warranty region, the policy assures the buyer is guaranteed a minimum coverage for $W$ units of time after sale and for $U$ units of usage. The warranty expires the first time instant both time and usage exceeds the limits $W$ and $U$ respectively. As a result, the number of replacements under warranty is given by

$$
E[N(R L)]=\frac{1}{1-\left[F_{1}(W)+F_{2}(U)-F(W, U)\right]}
$$

As a result, the expected warranty cost per remanufactured item is given by

$$
E\left[C_{d}(W ; R L)\right]=\frac{C_{S}(R L)}{1-\left[F_{1}(W)+F_{2}(U)-F(W, U)\right]}
$$

\subsubsection{Renewing FRW with Four Parameters Region}

The warranty region is characterized by four parameters $\left(W_{1}, W_{2}, U_{1}\right.$ and $\left.U_{2}\right)$ as shown in Figure $5(\mathrm{c})$. Under this policy, a buyer is assured of warranty coverage for a minimum time period $W_{1}$ and for a minimum usage $U_{1}$ and for a maximum cover for $W_{2}$ unit of time and $U_{2}$ unit of usage. As a result the number of replacements under warranty is given by

$$
E[N(R L)]=\frac{1}{1-\left[F\left(W_{1}, U_{2}\right)+F\left(W_{2}, U_{1}\right)-F\left(W_{1}, U_{1}\right)\right.}
$$


As a result, the expected warranty cost per remanufactured item is given by

$$
E\left[C_{d}(W ; R L)\right]=\frac{C_{S}(R L)}{1-\left[F\left(W_{1}, U_{2}\right)+F\left(W_{2}, U_{1}\right)-F\left(W_{1}, U_{1}\right)\right.}
$$

\subsubsection{Renewing FRW with Triangle Region}

The warranty region is characterized by a triangle shape as shown in Figure 5(d). The number of replacements under warranty is given by

$$
E[N(R L)]=\frac{1}{1-F(U)}
$$

As a result, the expected warranty cost per remanufactured item is given by

$$
E\left[C_{d}(W ; R L)\right]=\frac{C_{S}(R L)}{1-F(U)}
$$

\subsection{Renewing 2D Pro-Rata Warranty Policy}

Under this policy, if the remanufactured item fails in the warranty region, $\Omega$, a remanufactured replacement is supplied at reduced price. This can be viewed as a conditional refund since the refund is tied to a remanufactured replacement purchase. Similar to FRW policy, two different forms for warranty region and refund function, $R(t, x)$ are been consider for PRW.

\subsubsection{Renewing PRW with Rectangle Region}

The warranty region is characterized by a rectangle shape as shown in Figure 5(a) and the refund function is given by

$$
R(t, x)=\left\{\begin{array}{c}
C_{S}(R L) \times\left[1-\frac{t}{W}\right] \times\left[1-\frac{x}{U}\right] \quad \text { if }(t, x) \in \Omega \\
0 \quad \text { if }(t, x) \in \Omega
\end{array}\right.
$$

As a result, the expected warranty cost per remanufactured item is given by

$$
E\left[C_{d}(W ; R L)\right]=C_{S}(R L) \times\left[F(W, U)-\frac{\int_{0}^{U} \int_{0}^{W}\left[t_{1} U+\left(W-t_{1}\right) x_{1}\right] d F\left(t_{1}, x_{1}\right)}{W U[1-F(W, U)]}\right.
$$




\subsubsection{Renewing PRW with Infinite Strips Region}

The warranty region is characterized by two infinite dimensional strips as shown in Figure 5(b) and the refund function is given by

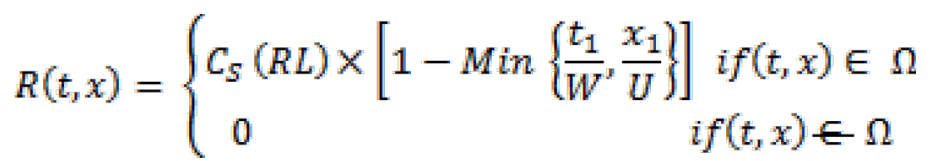

As a result, the expected warranty cost per remanufactured item is given by

$$
E\left[C_{d}(W ; R L)\right]=C_{S}(R L) \times\left\{F(W, U)-\frac{\iint_{\Omega}^{0}\left[1-\operatorname{Min}\left(\frac{t}{k}, \frac{x}{L}\right)\right] d F\left(t_{1}, x_{1}\right)}{1-\left[F_{1}(W)+F_{2}(U)-F(W, U)\right]}\right\}
$$

\subsection{Renewing FRW-PRW Combination Policy}

In combination warranty, the warranty region, $\Omega$, consists of two disjoint sub-regions $\Omega_{1}$ and $\Omega_{2}$ where the warranty terms are different for each region. If a failure occurs in $\Omega_{1}$, the buyer is entitle to FRW policy. While, if a failure occurs in $\Omega_{2}$, the buyer is entitle to PRW policy. The replacement is covered with a new warranty identical to that of the original item. Similar to PRW policy, two different forms for warranty region and refund function, $R(t, x)$ are been consider for FRW-PRW combination policy as shown in Figure 6.

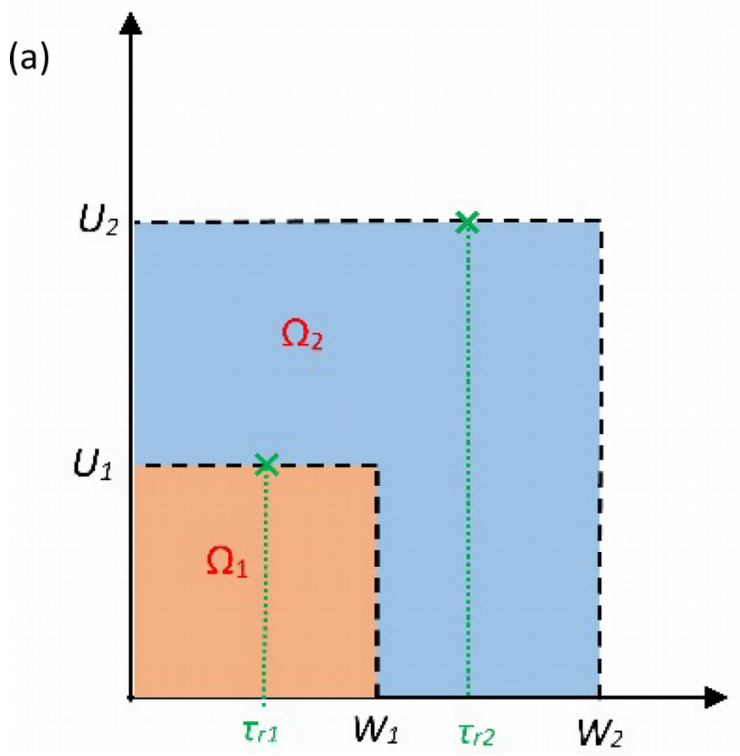

(b)

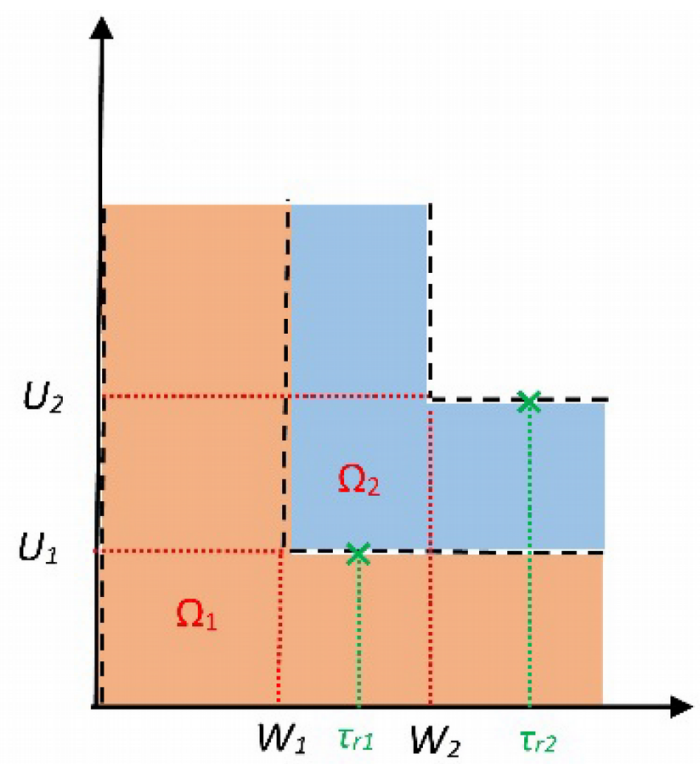

Figure 6. Warranty Regions for Combination Warranty Policy 


\subsubsection{Renewing FRW-PRW Combination with Rectangle Region}

The warranty region is characterized by two rectangle shape sub-region as shown in Figure 6(a). The warranty expires the first time a failure occurs outside the rectangle. The refund function is given by

$$
R(t, x)=\left\{\begin{array}{cc}
C_{S}(R L) \times\left[1-\frac{t}{W_{2}}\right] \times\left[1-\frac{x-U_{1}}{U_{2}-U_{1}}\right] & \text { if } 0<t \leq W_{1} ; U_{1}<x \leq U_{2} \\
C_{S}(R L) \times\left[1-\frac{t-W_{1}}{W_{2}-W_{1}}\right] \times\left[1-\frac{x-U_{1}}{U_{2}-U_{1}}\right] & \text { if } W_{1}<t \leq W_{2} ; U_{1}<x \leq U_{2} \\
C_{S}(R L) \times\left[1-\frac{t-W_{1}}{W_{2}-W_{1}}\right] \times\left[1-\frac{x}{U_{2}}\right] & \text { if } W_{1}<t \leq W_{2} ; 0<x \leq U_{1}
\end{array}\right.
$$

The expected warranty cost per remanufactured item is given by

$$
\begin{aligned}
\mathrm{E}\left[C_{d}(W ; R L)\right]= & \iint_{\Omega_{1}}\left[E C\left(W_{1}-t, U_{1}-x, W_{2}-t, U_{2}-x\right)+C_{S}(R L)\right] d F(t, x) \\
& +\iint_{\Omega_{2}} R(t, x) d F(t, x)
\end{aligned}
$$

\subsubsection{Renewing FRW-PRW Combination with Infinite Strips Regions}

The warranty region is characterized by two infinite dimensional strips regions as shown in Figure 6(b). As a result the refund function is given by

$$
R(t, x)=\left\{\begin{array}{c}
C_{S}(R L) \times\left[1-\operatorname{Min}\left\{\frac{t-W_{1}}{W_{2}-W_{1}}, \frac{x-U_{1}}{U-U_{1}}\right\}\right] \text { if }(t, x) \in \Omega_{2} \\
\text { if }(t, x) \in \Omega
\end{array}\right.
$$

As a result, the expected warranty cost per remanufactured item is given by

$$
\begin{aligned}
E\left[C_{d}\left(W_{;} R L\right)\right] & =\int_{0}^{r_{1}}\left[C_{S}(R L) \times F\left(\tau_{r 1} \mid r\right)\right. \\
& \left.+\frac{\left.\int_{\tau_{r 1}}^{\tau_{r 2}}\left[C_{S}(R L)-C_{p}(R L)-R(t, r t)\right] d F(t \mid r)\right]}{1-F\left(\tau_{r 2} \mid r\right)}\right] d G(r) \\
& +\int_{r_{1}}^{\infty}\left[C_{S}(R L) \times F\left(W_{1} \mid r\right)\right. \\
& \left.+\frac{\left.\int_{W_{1}}^{W_{2}}\left[C_{S}(R L)-C_{p}(R L)-R(t, r t)\right] d F(t \mid r)\right]}{1-F\left(W_{2} \mid r\right)}\right] d G(r)
\end{aligned}
$$




\section{Results}

The results are divided into four sections. Section 10.1 deals with the evaluation of the effect of offering different warranty policies to help the decision maker choose the best warranty policy to offer. Section 10.2, shows a quantitative assessment of offering PM on warranty policies. Section 10.3 presents a quantitative assessment of the impact of SEPs on the warranty and maintenance costs and policies to the remanufacturer. Finally, section 10.4 presents a discussion about how to price remanufactured items using warranty and maintenance information.

\subsection{Remanufacturing Warranty Policies Evaluation}

In this section, the results to compute the expected number of failures and expected cost to the remanufacturer were obtained using the ARENA 14.5 program. We evaluate different warranty period with offering a preventive maintenance policy during each period.

\subsubsection{Renewable Free Replacement Warranty (FRW) Policy}

Table 4 presents the expected number of failures and cost for remanufactured AC and components for renewable FRW, PRW and Combination Policies. In Table 4, the expected number of failures represents the expected number of failed items per unit of sale. In other words, it is the average number of free replacements that the remanufacturer would have to provide during the warranty period per unit sold. Expected cost to the remanufacturer includes the cost of supplying the original item, Cs. Thus, the expected cost of warranty is calculated by subtracting $C s$ from the expected cost to remanufacturer. For example, from Table 4, for $W=0.5$ and $R L=1$, the warranty cost for $\mathrm{AC}$ is $\$ 61.10-C s=\$ 61.10-\$ 55.00$ $=\$ 6.10$ which is $([\$ 6.10 / \$ 55.00] \times 100)=11.09 \%$ of the cost of supplying the item, $C s$, which is significantly less than that $\$ 55.00$, Cs. This saving might be acceptable, but the corresponding values for longer warranties are much higher. For example, for $W=2$ years and $R L=1$, the corresponding percentage is $([|\$ 74.92-\$ 55.00| / \$ 55.00] \times 100)=36.22 \%$.

\subsubsection{Renewable Pro-Rata Warranty (PRW) Policy}

The results for PRW are also given in Table 4. Here too, the expected cost of warranty can be calculated as above. For example, the cost of warranty for 3 years remaining life $\mathrm{AC}$ with $W=2$ years will cost $\$ 121.27$ - $C s=\$ 121.27-\$ 55.00=\$ 66.27$ which is $120.49 \%$ of the cost of supplying the item, $C s$. 


\begin{tabular}{|c|c|c|c|c|c|c|c|}
\hline \multirow[b]{3}{*}{ Components } & \multirow[b]{3}{*}{$W^{*}$} & \multicolumn{6}{|c|}{ Renewable Free Replacement Warranty (FRW) } \\
\hline & & \multicolumn{3}{|c|}{ Expected frequancy of Failures } & \multicolumn{3}{|c|}{ Expected Cost to Remanufacturer } \\
\hline & & $R L^{*}=1$ & $R L=2$ & $R L=3$ & $R L=1$ & $R L=2$ & $R L=3$ \\
\hline \multirow{3}{*}{ Evaporator } & 0.5 & 0.5188 & 0.0034 & 0.0008 & $\$ 4.40$ & $\$ 5.04$ & $\$ 4.01$ \\
\hline & 1 & 0.104 & 0.0135 & 0.0061 & $\$ 4.89$ & $\$ 5.52$ & $\$ 4.11$ \\
\hline & 2 & 0.1557 & 0.03 & 0.021 & $\$ 7.32$ & $\$ 7.28$ & $\$ 4.23$ \\
\hline \multirow{3}{*}{ Control Box } & 0.5 & 0.5125 & 0.0032 & 0.0041 & $\$ 4.32$ & $\$ 5.01$ & $\$ 4.01$ \\
\hline & 1 & 0.1102 & 0.0133 & 0.0332 & $\$ 5.09$ & $\$ 5.38$ & $\$ 4.08$ \\
\hline & 2 & 0.1494 & 0.0299 & 0.1118 & $\$ 7.23$ & $\$ 7.14$ & $\$ 4.20$ \\
\hline \multirow{3}{*}{ Blower } & 0.5 & 0.5062 & 0.0031 & 0.0216 & $\$ 2.16$ & $\$ 2.02$ & $\$ 2.07$ \\
\hline & 1 & 0.0978 & 0.0136 & 0.1779 & $\$ 2.85$ & $\$ 3.59$ & $\$ 2.10$ \\
\hline & 2 & 0.1433 & 0.0303 & 0.5981 & $\$ 3.92$ & $\$ 4.41$ & $\$ 2.19$ \\
\hline \multirow{3}{*}{ Air Guide } & 0.5 & 0.5062 & 0.0014 & 0.1152 & $\$ 1.18$ & $\$ 1.16$ & $\$ 1.00$ \\
\hline & 1 & 0.0729 & 0.0138 & 0.9505 & $\$ 1.72$ & $\$ 1.58$ & $\$ 1.09$ \\
\hline & 2 & 0.1307 & 0.0264 & 0.3895 & $\$ 2.28$ & $\$ 2.25$ & $\$ 1.16$ \\
\hline \multirow{3}{*}{ Motor } & 0.5 & 0.4914 & 0.0032 & 0.6159 & $\$ 4.50$ & $\$ 4.32$ & $\$ 4.23$ \\
\hline & 1 & 0.1065 & 0.0133 & 0.7989 & $\$ 4.95$ & $\$ 4.61$ & $\$ 4.29$ \\
\hline & 2 & 0.15 & 0.0303 & 0.0167 & $\$ 6.96$ & $\$ 5.98$ & $\$ 4.34$ \\
\hline \multirow{3}{*}{ Condenser } & 0.5 & 0.5119 & 0.0034 & 0.7656 & $\$ 1.41$ & $\$ 1.20$ & $\$ 1.18$ \\
\hline & 1 & 0.0996 & 0.0135 & 0.8056 & $\$ 2.04$ & $\$ 1.72$ & $\$ 1.29$ \\
\hline & 2 & 0.1569 & 0.0303 & 0.0889 & $\$ 2.36$ & $\$ 1.98$ & $\$ 1.36$ \\
\hline \multirow{3}{*}{ Fan } & 0.5 & 0.5243 & 0.0031 & 0.7989 & $\$ 2.70$ & $\$ 2.28$ & $\$ 2.19$ \\
\hline & 1 & 0.1146 & 0.0133 & 0.1624 & $\$ 3.72$ & $\$ 2.67$ & $\$ 2.24$ \\
\hline & 2 & 0.1508 & 0.0302 & 0.4756 & $\$ 4.63$ & $\$ 3.69$ & $\$ 2.36$ \\
\hline \multirow{3}{*}{ Protector } & 0.5 & 0.5294 & 0.0034 & 0.5692 & $\$ 0.72$ & $\$ 0.55$ & $\$ 0.40$ \\
\hline & 1 & 0.0978 & 0.0133 & 0.8683 & $\$ 1.10$ & $\$ 0.90$ & $\$ 0.47$ \\
\hline & 2 & 0.1488 & 0.0303 & 0.8022 & $\$ 1.93$ & $\$ 1.30$ & $\$ 0.51$ \\
\hline \multirow{3}{*}{ Compressor } & 0.5 & 0.5113 & 0.0034 & 0.017 & $\$ 3.13$ & $\$ 2.93$ & $\$ 2.80$ \\
\hline & 1 & 0.1034 & 0.0135 & 0.0889 & $\$ 4.01$ & $\$ 3.78$ & $\$ 3.03$ \\
\hline & 2 & 0.15 & 0.0302 & 0.8056 & $\$ 5.49$ & $\$ 4.95$ & $\$ 3.13$ \\
\hline \multirow{3}{*}{$\mathrm{AC}$} & 0.5 & 0.608 & 0.0044 & 0.0003 & $\$ 61.10$ & $\$ 58.63$ & $\$ 58.10$ \\
\hline & 1 & 0.1563 & 0.0179 & 0.0028 & $\$ 63.77$ & $\$ 64.47$ & $\$ 60.83$ \\
\hline & 2 & 0.2048 & 0.0398 & 0.009 & $\$ 74.92$ & $\$ 73.82$ & $\$ 63.08$ \\
\hline
\end{tabular}




\begin{tabular}{|c|c|c|c|c|c|c|c|}
\hline \multirow[b]{3}{*}{ Components } & \multirow[b]{3}{*}{$W^{*}$} & \multicolumn{6}{|c|}{ Renewable Pro-Rata Warranty (PRW) } \\
\hline & & \multicolumn{3}{|c|}{ Expected frequancy of Failures } & \multicolumn{3}{|c|}{ Expected Cost to Remanufacturer } \\
\hline & & $R L^{*}=1$ & $R L=2$ & $R L=3$ & $R L=1$ & $R L=2$ & $R L=3$ \\
\hline \multirow{3}{*}{ Evaporator } & 0.5 & 1.0029 & 0.0065 & 0.0014 & $\$ 7.54$ & $\$ 8.63$ & $\$ 6.90$ \\
\hline & 1 & 0.2011 & 0.0261 & 0.012 & $\$ 8.37$ & $\$ 9.47$ & $\$ 7.03$ \\
\hline & 2 & 0.301 & 0.0581 & 0.0404 & $\$ 12.55$ & $\$ 12.47$ & $\$ 7.25$ \\
\hline \multirow{3}{*}{ Control Box } & 0.5 & 0.9909 & 0.0062 & 0.0079 & $\$ 7.39$ & $\$ 8.58$ & $\$ 6.89$ \\
\hline & 1 & 0.2131 & 0.0256 & 0.0643 & $\$ 8.72$ & $\$ 9.21$ & $\$ 6.97$ \\
\hline & 2 & 0.2889 & 0.0578 & 0.2163 & $\$ 12.40$ & $\$ 12.24$ & $\$ 7.20$ \\
\hline \multirow{3}{*}{ Blower } & 0.5 & 0.9788 & 0.006 & 0.0416 & $\$ 3.70$ & $\$ 3.47$ & $\$ 3.53$ \\
\hline & 1 & 0.189 & 0.0263 & 0.3437 & $\$ 4.86$ & $\$ 6.14$ & $\$ 3.61$ \\
\hline & 2 & 0.2769 & 0.0587 & 1.1563 & $\$ 6.73$ & $\$ 7.57$ & $\$ 3.75$ \\
\hline \multirow{3}{*}{ Air Guide } & 0.5 & 0.9788 & 0.0027 & 0.2227 & $\$ 2.04$ & $\$ 1.99$ & $\$ 1.69$ \\
\hline & 1 & 0.1409 & 0.0266 & 1.8377 & $\$ 2.94$ & $\$ 2.71$ & $\$ 1.87$ \\
\hline & 2 & 0.2528 & 0.0508 & 0.7529 & $\$ 3.89$ & $\$ 3.88$ & $\$ 1.99$ \\
\hline \multirow{3}{*}{ Motor } & 0.5 & 0.9499 & 0.0062 & 1.1908 & $\$ 7.73$ & $\$ 7.39$ & $\$ 7.23$ \\
\hline & 1 & 0.2058 & 0.0255 & 1.5445 & $\$ 8.49$ & $\$ 7.92$ & $\$ 7.36$ \\
\hline & 2 & 0.2902 & 0.0587 & 0.0321 & $\$ 11.92$ & $\$ 10.24$ & $\$ 7.42$ \\
\hline \multirow{3}{*}{ Condenser } & 0.5 & 0.9895 & 0.0066 & 1.4802 & $\$ 2.41$ & $\$ 2.06$ & $\$ 2.01$ \\
\hline & 1 & 0.1927 & 0.026 & 1.5573 & $\$ 3.50$ & $\$ 2.94$ & $\$ 2.22$ \\
\hline & 2 & 0.3035 & 0.0586 & 0.1721 & $\$ 4.05$ & $\$ 3.40$ & $\$ 2.33$ \\
\hline \multirow{3}{*}{ Fan } & 0.5 & 1.0137 & 0.006 & 1.5445 & $\$ 4.62$ & $\$ 3.89$ & $\$ 3.75$ \\
\hline & 1 & 0.2215 & 0.0258 & 0.3139 & $\$ 6.36$ & $\$ 4.56$ & $\$ 3.85$ \\
\hline & 2 & 0.2915 & 0.0583 & 0.9195 & $\$ 7.93$ & $\$ 6.35$ & $\$ 4.05$ \\
\hline \multirow{3}{*}{ Protector } & 0.5 & 1.0233 & 0.0065 & 1.1004 & $\$ 1.22$ & $\$ 0.95$ & $\$ 0.68$ \\
\hline & 1 & 0.189 & 0.026 & 1.6787 & $\$ 1.90$ & $\$ 1.55$ & $\$ 0.82$ \\
\hline & 2 & 0.2877 & 0.0587 & 1.551 & $\$ 3.31$ & $\$ 2.22$ & $\$ 0.89$ \\
\hline \multirow{3}{*}{ Compressor } & 0.5 & 0.9883 & 0.0065 & 0.0328 & $\$ 5.35$ & $\$ 5.02$ & $\$ 4.80$ \\
\hline & 1 & 0.1998 & 0.026 & 0.1721 & $\$ 6.90$ & $\$ 6.47$ & $\$ 5.21$ \\
\hline & 2 & 0.2902 & 0.0584 & 1.5573 & $\$ 9.39$ & $\$ 8.49$ & $\$ 5.38$ \\
\hline \multirow{3}{*}{$\mathrm{AC}$} & 0.5 & 1.1753 & 0.0087 & 0.0008 & $\$ 92.04$ & $\$ 87.50$ & $\$ 111.67$ \\
\hline & 1 & 0.3022 & 0.0347 & 0.0054 & $\$ 96.05$ & $\$ 96.22$ & $\$ 116.90$ \\
\hline & 2 & 0.3961 & 0.0773 & 0.0176 & $\$ 112.84$ & $\$ 110.19$ & $\$ 121.27$ \\
\hline
\end{tabular}




\begin{tabular}{|c|c|c|c|c|c|c|c|}
\hline \multirow{3}{*}{ Components } & \multirow{3}{*}{$W^{*}$} & \multicolumn{6}{|c|}{ Renewable Combination FRW/PRW } \\
\hline & & \multicolumn{3}{|c|}{ Expected frequancy of Failures } & \multicolumn{3}{|c|}{ Expected Cost to Remanufacturer } \\
\hline & & $R L^{*}=1$ & $R L=2$ & $R L=3$ & $R L=1$ & $R L=2$ & $R L=3$ \\
\hline \multirow{3}{*}{ Evaporator } & 0.5 & 0.4407 & 0.0028 & 0.0007 & $\$ 12.35$ & $\$ 14.14$ & $\$ 11.31$ \\
\hline & 1 & 0.0883 & 0.0115 & 0.0052 & $\$ 13.72$ & $\$ 15.51$ & $\$ 11.52$ \\
\hline & 2 & 0.1322 & 0.0256 & 0.0179 & $\$ 20.57$ & $\$ 20.44$ & $\$ 11.88$ \\
\hline \multirow{3}{*}{ Control Box } & 0.5 & 0.4355 & 0.0028 & 0.0034 & $\$ 12.11$ & $\$ 14.06$ & $\$ 11.28$ \\
\hline & 1 & 0.0937 & 0.0113 & 0.0282 & $\$ 14.29$ & $\$ 15.10$ & $\$ 11.41$ \\
\hline & 2 & 0.127 & 0.0254 & 0.095 & $\$ 20.31$ & $\$ 20.05$ & $\$ 11.80$ \\
\hline \multirow{3}{*}{ Blower } & 0.5 & 0.4301 & 0.0026 & 0.0183 & $\$ 6.07$ & $\$ 5.68$ & $\$ 5.78$ \\
\hline & 1 & 0.0831 & 0.0115 & 0.1511 & $\$ 7.96$ & $\$ 10.06$ & $\$ 5.91$ \\
\hline & 2 & 0.1217 & 0.0257 & 0.5082 & $\$ 11.02$ & $\$ 12.40$ & $\$ 6.15$ \\
\hline \multirow{3}{*}{ Air Guide } & 0.5 & 0.4301 & 0.0011 & 0.098 & $\$ 3.35$ & $\$ 3.27$ & $\$ 2.78$ \\
\hline & 1 & 0.0619 & 0.0118 & 0.8077 & $\$ 4.82$ & $\$ 4.44$ & $\$ 3.06$ \\
\hline & 2 & 0.1111 & 0.0223 & 0.3309 & $\$ 6.38$ & $\$ 6.35$ & $\$ 3.27$ \\
\hline \multirow{3}{*}{ Motor } & 0.5 & 0.4174 & 0.0028 & 0.5233 & $\$ 12.66$ & $\$ 12.11$ & $\$ 11.85$ \\
\hline & 1 & 0.0904 & 0.0113 & 0.6788 & $\$ 13.90$ & $\$ 12.97$ & $\$ 12.06$ \\
\hline & 2 & 0.1275 & 0.0257 & 0.0141 & $\$ 19.53$ & $\$ 16.78$ & $\$ 12.16$ \\
\hline \multirow{3}{*}{ Condenser } & 0.5 & 0.435 & 0.0029 & 0.6506 & $\$ 3.94$ & $\$ 3.37$ & $\$ 3.29$ \\
\hline & 1 & 0.0847 & 0.0115 & 0.6845 & $\$ 5.73$ & $\$ 4.82$ & $\$ 3.63$ \\
\hline & 2 & 0.1334 & 0.0257 & 0.0755 & $\$ 6.64$ & $\$ 5.58$ & $\$ 3.81$ \\
\hline \multirow{3}{*}{ Fan } & 0.5 & 0.4455 & 0.0026 & 0.6788 & $\$ 7.57$ & $\$ 6.38$ & $\$ 6.15$ \\
\hline & 1 & 0.0973 & 0.0113 & 0.1381 & $\$ 10.43$ & $\$ 7.47$ & $\$ 6.30$ \\
\hline & 2 & 0.1281 & 0.0256 & 0.4042 & $\$ 12.99$ & $\$ 10.40$ & $\$ 6.64$ \\
\hline \multirow{3}{*}{ Protector } & 0.5 & 0.4497 & 0.0028 & 0.4836 & $\$ 2.00$ & $\$ 1.56$ & $\$ 1.12$ \\
\hline & 1 & 0.0831 & 0.0113 & 0.7379 & $\$ 3.11$ & $\$ 2.54$ & $\$ 1.35$ \\
\hline & 2 & 0.1265 & 0.0257 & 0.6815 & $\$ 5.42$ & $\$ 3.63$ & $\$ 1.45$ \\
\hline \multirow{3}{*}{ Compressor } & 0.5 & 0.4345 & 0.0028 & 0.0144 & $\$ 8.77$ & $\$ 8.22$ & $\$ 7.86$ \\
\hline & 1 & 0.0878 & 0.0115 & 0.0755 & $\$ 11.31$ & $\$ 10.61$ & $\$ 8.53$ \\
\hline & 2 & 0.1275 & 0.0257 & 0.6845 & $\$ 15.38$ & $\$ 13.90$ & $\$ 8.82$ \\
\hline \multirow{3}{*}{$\mathrm{AC}$} & 0.5 & 0.3037 & 0.002 & 0.0002 & $\$ 150.79$ & $\$ 143.35$ & $\$ 182.96$ \\
\hline & 1 & 0.0614 & 0.008 & 0.0011 & $\$ 157.36$ & $\$ 157.64$ & $\$ 191.51$ \\
\hline & 2 & 0.0891 & 0.018 & 0.0041 & $\$ 184.87$ & $\$ 180.52$ & $\$ 198.67$ \\
\hline
\end{tabular}

Table 4. Expected number of failures and cost for remanufactured AC and components 


\subsubsection{Combination Warranty (FRW-PRW) Policy}

Here too the results given in Table 4 the expected cost of warranty can be calculated in a similar manner as above. For example, the cost of warranty for 3 years remaining life $\mathrm{AC}$ with $W=2.0$ years will cost $\$ 198.67-\$ 55.00=\$ 143.67$ which is $261.23 \%$ saving in the cost of supplying the item, Cs.

\subsection{Preventive Maintenance Evaluation}

In order to assess the impact of PM on warranty cost, pairwise t tests were carried out for each performance measure. Table 5 and Table 6 present all models costs for conventional, warranty models with/ without PM respectively. According to these tables, PM achieves significant savings in holding, backorder, disassembly, disposal, remanufacturing, transportation, warranty, PM costs and number of warranty claims. In addition, SEPs provide significant improvements in total revenue and profit. According to Table 5 and Table 6, offering PM helps remanufacturer achieve saving 18\%, 21\%, 19\% and 18\% in total cost for Conventional, SEM with FRW, SEM with FRW, and SEM with FRW respectively.

\begin{tabular}{|c|c|c|c|c|}
\hline \multirow[b]{2}{*}{ Performance Measure } & \multicolumn{4}{|c|}{ Mean Value with Warranty (PM offered) } \\
\hline & $\begin{array}{l}\text { Conventional } \\
\text { Model }\end{array}$ & $\begin{array}{l}\text { Sensor Embedded } \\
\text { Model with FRW }\end{array}$ & $\begin{array}{l}\text { Sensor Embedded } \\
\text { Model with PRW }\end{array}$ & $\begin{array}{c}\text { Sensor Embedded } \\
\text { Model } \\
\text { FRW/PRW }\end{array}$ \\
\hline Holding Cost & $\$ 250,257.03$ & $\$ 150,774.37$ & $\$ 158,555.63$ & $\$ 159,196.12$ \\
\hline Backorder Cost & $\$ 46,422.30$ & $\$ 30,327.20$ & $\$ 31,892.35$ & $\$ 32,021.18$ \\
\hline Disassembly Cost & $\$ 540,380.03$ & $\$ 321,547.48$ & $\$ 338,142.11$ & $\$ 339,508.05$ \\
\hline Disposal Cost & $\$ 87,538.68$ & $\$ 60,884.22$ & $\$ 64,026.37$ & $\$ 64,285.00$ \\
\hline Testing Cost & $\$ 161,174.99$ & $\mathrm{~N} / \mathrm{A}$ & $\mathrm{N} / \mathrm{A}$ & $\mathrm{N} / \mathrm{A}$ \\
\hline Remanufacturing Cost & $\$ 1,857,829.27$ & $\$ 898,968.38$ & $\$ 945,362.90$ & $\$ 949,181.73$ \\
\hline Transportation Cost & $\$ 46,877.95$ & $\$ 31,606.49$ & $\$ 33,237.66$ & $\$ 33,371.92$ \\
\hline Warranty Cost & $\$ 117,704.65$ & $\$ 9,025.85$ & $\$ 21,743.84$ & $\$ 15,885.82$ \\
\hline Number of Claims & 55,722 & 11,981 & 15,487 & 14,793 \\
\hline Preventive Maintenance Cost & $\$ 9,087.25$ & $\$ 1,731.24$ & $\$ 3,181.98$ & $\$ 2,771.73$ \\
\hline Total Cost & $\$ 3,117,272.15$ & $\$ 1,504,865.22$ & $\$ 1,596,142.83$ & $\$ 1,596,221.55$ \\
\hline Total Revenue & $\$ 4,693,569.22$ & $\$ 6,452,158.07$ & $\$ 4,933,609.46$ & $\$ 6,677,871.58$ \\
\hline Profit & $\$ 1,576,297.06$ & $\$ 4,947,292.85$ & $\$ 3,337,466.64$ & $\$ 5,081,650.03$ \\
\hline
\end{tabular}

Table 5. Results of performance measures for different models with warranty and preventive maintenance

The lowest average value of warranty, PM costs and the number of warranty claims during the warranty period for remanufactured ACs across all policies are \$7,094.30, $\$ 1,724.32$ and 9,339 claims 
respectively for the Sensor Embedded Model with FRW warranty policy. Whereas the conventional $\mathrm{AC}$ has the worst values for the warranty, PM costs and the number of warranty claims during the warranty period.

\begin{tabular}{|c|c|c|c|c|}
\hline \multirow[b]{2}{*}{ Performance Measure } & \multicolumn{4}{|c|}{ Mean Value with Warranty (No PM offered) } \\
\hline & $\begin{array}{l}\text { Conventional } \\
\text { Model }\end{array}$ & $\begin{array}{l}\text { Sensor Embedded } \\
\text { Model with FRW }\end{array}$ & $\begin{array}{l}\text { Sensor Embedded } \\
\text { Model with PRW }\end{array}$ & $\begin{array}{c}\text { Sensor Embedded } \\
\text { Model } \\
\text { FRW/PRW }\end{array}$ \\
\hline Holding Cost & $\$ 295,303.30$ & $\$ 182,436.99$ & $\$ 188,681.20$ & $\$ 187,851.42$ \\
\hline Backorder Cost & $\$ 54,778.31$ & $\$ 36,695.91$ & $\$ 37,951.90$ & $\$ 37,784.99$ \\
\hline Disassembly Cost & $\$ 637,648.44$ & $\$ 389,072.45$ & $\$ 402,389.11$ & $\$ 400,619.50$ \\
\hline Disposal Cost & $\$ 103,295.64$ & $\$ 73,669.91$ & $\$ 76,191.38$ & $\$ 75,856.30$ \\
\hline Testing Cost & $\$ 190,186.49$ & $\mathrm{~N} / \mathrm{A}$ & $\mathrm{N} / \mathrm{A}$ & $\mathrm{N} / \mathrm{A}$ \\
\hline Remanufacturing Cost & $\$ 2,192,238.54$ & $\$ 1,087,751.74$ & $\$ 1,124,981.85$ & $\$ 1,120,034.44$ \\
\hline Transportation Cost & $\$ 55,315.98$ & $\$ 38,243.85$ & $\$ 39,552.82$ & $\$ 39,378.87$ \\
\hline Warranty Cost & $\$ 138,891.49$ & $\$ 10,921.28$ & $\$ 25,875.17$ & $\$ 18,745.27$ \\
\hline Number of Claims & 65,752 & 24,497 & $28,429.53$ & 27,456 \\
\hline Total Cost & $\$ 3,667,658.18$ & $\$ 1,818,792.13$ & $\$ 1,895,623.42$ & $\$ 1,880,270.79$ \\
\hline Total Revenue & $\$ 3,754,855.38$ & $\$ 5,548,855.94$ & $\$ 4,094,895.85$ & $\$ 5,409,075.98$ \\
\hline Profit & $\$ 87,197.19$ & $\$ 3,730,063.81$ & $\$ 2,199,272.43$ & $\$ 3,528,805.19$ \\
\hline
\end{tabular}

Table 6. Results of performance measures for different models with warranty

\subsection{Sensor Embedded Evaluation}

\subsubsection{Effect of SEPs on Warranty Cost}

In order to assess the impact of SEPs on warranty cost, pairwise $t$ tests were carried out for each performance measure. Table 5 presents ninety-five percent confidence interval, $t$ value and $p$ value for each test. According to these tables, SEPs achieve statistically significant savings in holding, backorder, disassembly, disposal, testing, remanufacturing and transportation costs. In addition, SEPs provide statistically significant improvements in total revenue and profit. According to Table 6 , the lowest average value of warranty costs and the number of warranty claims during the warranty period for remanufactured ACs across all policies are $\$ 9,025.85$ and 11,981 claims respectively for the FRW warranty policy. If a comparison made between the conventional product model and SEPs with PRW warranty (worst policy case in term of cost). The SEPs model saved around $81.37 \%$ and $71.97 \%$ in warranty cost and number of claim respectively for SEPs model without PM and $81.53 \%$ and $72.21 \%$ for SEPs model with PM. 


\subsubsection{Renewable Pro-Rata Warranty (PRW) Policy}

MINITAB-17 program was used to carry out one-way analyses of variance (ANOVA) and Tukey pairwise comparisons for all the results in this section. ANOVA was used in order to determine whether there are any significant differences between the warranty costs, number of claims and PM costs for the four different models viz., conventional model, SEPs with FRW, SEPs with PRW and SEPs with FRW/PRW, while the Tukey pairwise comparisons was conducted to identify which models are similar and which models are not. Table 7 shows that there is a significant difference in warranty costs between different warranty policies. Tukey test shows that all the models are different and the SEP model with FRW policy has the lowest warranty cost. In addition, there is a significant difference in the number of warranty claims between different warranty policies (see Table 8). The FRW policy has the lowest number of claims. Finally, Table 9 shows that there is a significant difference in PM costs between different warranty policies. Tukey test shows that all models are different and the SEP model with FRW policy has the lowest costs. These results can be useful in the determining the economical warranty policy associated with embedding sensors in Acs.

\section{ANOVA: Warranty Cost}

Null hypothesis All means are equal.

Alternative hypothesis At least one mean is different.

Significance level $\alpha=0.05$.

\begin{tabular}{|c|c|c|c|c|c|}
\hline \multicolumn{6}{|c|}{ SUMMARY } \\
\hline Models & Count & Sum & Average & StDev & $95 \% \mathrm{CI}$ \\
\hline Conventional Model & 2000 & $234,999,053$ & $117,704.65$ & 290.55 & $(117487,117512)$ \\
\hline SEP Model FRW & 2000 & $19,012,894$ & $9,025.85$ & 288.00 & $(9493.74,9519.15)$ \\
\hline SEP Model PRW & 2000 & $42,991,749$ & $21,743.84$ & 293.17 & $(21483.2,21508.6)$ \\
\hline SEP Model FRW/PRW & 2000 & $30,995,719$ & $15,885.82$ & 287.56 & $(15485.2,15510.6)$ \\
\hline \multicolumn{6}{|c|}{ ANOVA } \\
\hline Source of Variation & SS & df & MS & F-Value & P-value \\
\hline Model & $1.57496 \mathrm{E}+13$ & 3 & $5.24986 \mathrm{E}+12$ & 62499126.07 & 0.000 \\
\hline Error & 671655610 & 7996 & 83999 & & \\
\hline Total & $1.57503 \mathrm{E}+13$ & 7999 & & & \\
\hline \multicolumn{6}{|c|}{$\begin{array}{l}\text { Tukey Pairwise Comparisons. } \\
\text { Grouping Information Using the Tukey Method and 95\% Confidence. }\end{array}$} \\
\hline Model & & $\mathbf{N}$ & Mean & Grouping & \\
\hline Conventional Model & & 2000 & $117,704.65$ & A & \\
\hline SEP Model FRW & & 2000 & $9,025.85$ & B & \\
\hline SEP Model PRW & & 2000 & $21,743.84$ & $\mathrm{C}$ & \\
\hline SEP Model FRW/PRW & & 2000 & $15,885.82$ & $\mathrm{D}$ & \\
\hline
\end{tabular}

Table 7. ANOVA Table and Tukey Pairwise Comparisons for Warranty Cost 


\section{ANOVA: Warranty Claims}

Null hypothesis All means are equal.

Alternative hypothesis At least one mean is different.

Significance level $\alpha=0.05$.

\begin{tabular}{|c|c|c|c|c|c|}
\hline \multicolumn{6}{|c|}{ SUMMARY } \\
\hline Models & Count & Sum & Average & StDev & $95 \% \mathrm{CI}$ \\
\hline Conventional Model & 2000 & $111,000,028$ & 55,722 & 284.38 & $(55491.8,55508.3)$ \\
\hline SEP Model FRW & 2000 & $23,503,224$ & 11,981 & 140.92 & $(11743.4,11759.9)$ \\
\hline SEP Model PRW & 2000 & $31,506,965$ & 15,487 & 144.38 & $(15745.2,15761.7)$ \\
\hline SEP Model FRW/PRW & 2000 & $29,503,360$ & 14,793 & 143.00 & $(14743.4,14759.9)$ \\
\hline
\end{tabular}

\begin{tabular}{|l|r|r|r|r|r|}
\hline \multicolumn{7}{|c|}{ ANOVA } \\
\hline Source of Variation & \multicolumn{1}{|c|}{ SS } & df & \multicolumn{1}{c|}{ MS } & \multicolumn{1}{c|}{ F-Value } & P-value \\
\hline Model & $2.59008 \mathrm{E}+12$ & 3 & $8.63359 \mathrm{E}+11$ & 24316482.90 & 0.000 \\
\hline Error & 283898791 & 7996 & 35505 & & \\
\hline Total & $2.59036 \mathrm{E}+12$ & 7999 & & & \\
\hline
\end{tabular}

Tukey Pairwise Comparisons.

Grouping Information Using the Tukey Method and 95\% Confidence.

\begin{tabular}{|l|r|r|c|}
\hline \multicolumn{1}{|c|}{ Model } & N & Mean & Grouping \\
\hline Conventional Model & 2000 & 55,722 & A \\
\hline SEP Model FRW & 2000 & 11,981 & B \\
\hline SEP Model PRW & 2000 & 15,487 & C \\
\hline SEP Model FRW/PRW & 2000 & 14,793 & D \\
\hline \\
Means that do not share a letter are significantly different.
\end{tabular}

Table 8. ANOVA Table and Tukey Pairwise Comparisons for Number of Claims

\section{ANOVA: Preventive Maintenance}

Null hypothesis All means are equal.

Alternative hypothesis At least one mean is different.

Significance level $\alpha=0.05$.

\begin{tabular}{|l|r|r|r|r|r|}
\hline \multicolumn{7}{|c|}{ Models } & \multicolumn{1}{c|}{ SUMMARY } \\
\hline Conventional Model & 2000 & $18,500,571$ & $9,087.25$ & \multicolumn{1}{c|}{ StDev } & \multicolumn{1}{c|}{$95 \%$ CI } \\
\hline SEP Model FRW & 2000 & $3,500,607$ & $1,731.24$ & 29.59 & $(1744.76,1755.85)$ \\
\hline SEP Model PRW & 2000 & $6,498,581$ & $3,181.98$ & 144.12 & $(3243.74,3254.84)$ \\
\hline SEP Model FRW/PRW & 2000 & $5,502,922$ & $2,771.73$ & 145.07 & $(2745.91,2757.01)$ \\
\hline
\end{tabular}

\begin{tabular}{|l|r|r|r|r|r|}
\hline \multicolumn{7}{|c|}{ ANOVA } \\
\hline Source of Variation & \multicolumn{1}{|c|}{ SS } & df & \multicolumn{1}{c|}{ MS } & \multicolumn{1}{c|}{ F-Value } & P-value \\
\hline Model & 68996751725 & 3 & 22998917242 & 1436256.82 & 0.000 \\
\hline Error & 128040710 & 7996 & 16013 & & \\
\hline Total & 69124792435 & 7999 & & &
\end{tabular}

Tukey Pairwise Comparisons.

Grouping Information Using the Tukey Method and 95\% Confidence.

\begin{tabular}{|l|r|r|l|}
\hline \multicolumn{1}{|c|}{ Model } & N & Mean & Grouping \\
\hline Conventional Model & 2000 & $9,087.25$ & A \\
\hline SEP Model FRW & 2000 & $1,731.24$ & B \\
\hline SEP Model PRW & 2000 & $3,181.98$ & C \\
\hline SEP Model FRW/PRW & 2000 & $2,771.73$ & D \\
\hline \multicolumn{2}{|l}{} \\
\hline
\end{tabular}

Table 9. ANOVA Table and Tukey Pairwise Comparisons for Preventive Maintenance 


\section{Conclusions}

Sensor embedded products utilize sensors implanted into products during their production process. Sensors are useful in predicting the best warranty policy and warranty period to offer a customer for the remanufactured components and products. The conditions and remaining lives of components and products can be estimated prior to offering a warranty based on the data provided by the sensors. This helps reduce the number of claims during warranty periods, determines the right preventive maintenance (PM) policy and eliminates unnecessary costs inflicted on the remanufacturer. The renewing, one-dimensional Free Replacement Warranty (FRW), Pro-Rata Warranty (PRW) and combination FRW/PRW policies' costs for remanufactured products and components were evaluated with/without offering PM for different periods in this paper. To that end, the effect of offering renewable, twodimensional, Free Replacement Warranty (FRW) or Pro-Rata Warranty (PRW) or Combination FRW/PRW warranty policies to each disassembled component and sensor embedded remanufactured product was examined and the impact of sensor embedded products on warranty costs was assessed. A case study and varying simulation scenarios were examined and presented to illustrate the model's applicability.

\section{References}

Alqahtani, A.Y., \& Gupta, S.M. (2015a). End-of-Life Product Warranty, Proceedings of Northeast Decision Sciences Institute (NEDSI) Conference. Cambridge, MA.

Alqahtani, A.Y., \& Gupta, S.M. (2015b). Warranty Policy Analysis for End-Of-Life Product in Reverse Supply Chain, Proceedings of Production and Operations Management Society (POMS) 26th annual Conference. Washington D.C.

Alqahtani, A.Y., \& Gupta, S.M. (2015c). Extended Warranty Analysis for Remanufactured Products, Proceedings of International Conference on Remanufacturing (IcoR). Amsterdam, the Netherlands.

Alqahtani, A.Y., \& Gupta, S.M. (2016a). Non-Renewable Basic Two-Dimensional Warranty Policy Analysis for End-Of-Life Product in Reverse Supply Chain, Proceedings of Northeast Decision Sciences Institute (NEDSI) Conference. Alexandria, Va.

Alqahtani, A.Y., \& Gupta, S.M. (2016b). Two-Dimensional Warranty for an End-of-Life Derived Products, Proceedings of Production and Operations Management Society (POMS) 27th annual Conference. Orlando, FL. 
Alqahtani, A.Y., \& Gupta, S.M. (2016c). Renewable Basic One-Dimensional Warranty Policies Analysis for End-of-Life Product in Reverse Supply Chain, Proceedings of Institute of Industrial \& Systems Engineers (IISE). Anaheim, CA.

Alqahtani, A.Y., \& Gupta, S.M. (2017). Warranty Cost Analysis within Sustainable Supply Chain. In Akkucuk, U. (Ed.). Ethics and Sustainability in Global Supply Chain Management (1-25). Hershey, PA: IGI Global. https://doi.org/10.4018/978-1-5225-2036-8.ch001

Alqahtani, A.Y., Gupta, S.M., \& Nakashima, K. (2014). Performance Analysis of Advanced Remanufacture-To-Order, Disassembly-To-Order and Refurbishment-To-Order System. Innovation and Supply Chain Management, 8(4), 140-149. https://doi.org/10.14327/iscm.8.140

Balachander, S. (2001). Warranty signalling and reputation. Management Science, 47(9), 1282-1289. https://doi.org/10.1287/mnsc.47.9.1282.9783

Ben-Mabrouk, A., Chelbi, A., \& Radhoui, M. (2016). Optimal imperfect preventive maintenance policy for equipment leased during successive periods. International Journal of Production Research, 1-16. https://doi.org/10.1080/00207543.2016.1146417

Blischke, W. (Ed.) (1993). Warranty cost analysis. CRC Press.

Cheng, F.T., Huang, G.W., Chen, C.H. \& Hung, M.H. (2004). A generic embedded device for retrieving and transmitting information of various customized applications, Proceedings of the IEEE International Conference on Robotics and Automation. New Orleans, LA. 978-983.

Fang, H.C., Ong, S.K., \& Nee, A.Y.C. (2014). Use of Embedded Smart Sensors in Products to Facilitate Remanufacturing, In Nee, A.Y.C. (Eds.). Handbook of Manufacturing Engineering and Technology (3265-3290), London: Springer-Verlag. https://doi.org/10.1007/978-1-4471-4976-7_85-1

Gal-Or, E. (1989). Warranties as a signal of quality. Canadian Journal of Economics, 22(1), 50-61. https://doi.org/10.2307/135459

Garg, A., \& Deshmukh, S.G. (2006). Maintenance management: literature review and directions. Journal of Quality in Maintenance Engineering, 12(3), 205-238. https://doi.org/10.1108/13552510610685075

Gungor, A., \& Gupta, S.M. (1999). Issues in environmentally conscious manufacturing and product recovery: a survey. Computers and Industrial Engineering, 36, 811-853. https://doi.org/10.1016/S03608352(99)00167-9

Gungor, A., \& Gupta, S.M. (2002). Disassembly line in product recovery. International Journal of Production Research, 40, 2569-2589. https://doi.org/10.1080/00207540210135622 
Gupta, S.M. (2013). Reverse supply chains: issues and analysis. CRC Press. https://doi.org/10.1201/b13749

Gupta, S.M., \& Lambert, A.J.D. (Eds.) (2008). Environment conscious manufacturing. Boca Raton: CRC Press.

Gupta, S.M., Imtanavanich, P., \& Nakashima, K. (2009). Using neural networks to solve a disassembly-to-order problem, International Journal of Biomedical Soft Computing and Human Sciences, 15, $67-71$.

Heal, G. (1977). Guarantees and risk-sharing. The Review of Economic Studies, 44(3), 549-560. https://doi.org/10.2307/2296907

Herzog, M.A., Marwala, T., \& Heyns, P.S. (2009). Machine and component residual life estimation through the application of neural networks, Reliability Engineering and System Safety, 94, 479-489. https://doi.org/10.1016/j.ress.2008.05.008

Ilgin, M.A., \& Gupta, S.M. (2010a). Comparison of economic benefits of sensor embedded products and conventional products in a multi-product disassembly line. Computers and Industrial Engineering, 59, 748763. https://doi.org/10.1016/j.cie.2010.07.031

Ilgin, M.A., \& Gupta, S.M. (2010b). Environmentally conscious manufacturing and product recovery (ECMPRO): A review of the state of the art. Journal of Environmental Management, 91, 563-591. https://doi.org/10.1016/j.jenvman.2009.09.037

Ilgin, M.A., \& Gupta, S.M. (2010c). Evaluating the impact of sensor-embedded products on the performance of an air conditioner disassembly line. The International Journal of Advanced Manufacturing Technology, 53, 1199-1216. https://doi.org/10.1007/s00170-010-2891-0

Ilgin, M.A., \& Gupta, S.M. (2011). Performance improvement potential of sensor embedded products in environmental supply chains. Resources, Conservation and Recycling, 55, 580-592.

https://doi.org/10.1016/j.resconrec.2010.05.001

Ilgin, M.A, Gupta, S.M., \& Battaïa, O. (2015). Use of MCDM techniques in environmentally conscious manufacturing and product recovery: State of the art. Journal of Manufacturing Systems, 37(3), 746-758. https://doi.org/10.1016/j.jmsy.2015.04.010

Imtanavanich, P., \& Gupta, S.M. (2006). Calculating disassembly yields in a multicriteria decision-making environment for a disassembly to order system. In Lawrence, K.D., \& Klimberg, R.K. (Eds.). Applications of Management Science: In Productivity, Finance, and Operations (109-125). Elsevier Ltd.

Inderfurth, K., \& Langella, I.M. (2006). Heuristics for solving disassemble-to-order problems with stochastic yields. OR Spectrum, 28, 73-99. https://doi.org/10.1007/s00291-005-0007-2 
Karlsson, B. (1997). A distributed data processing system for industrial recycling, in Proceedings of IEEE Instrumentation and Measurement Technology Conference. Ottawa, Canada. 197-200. https://doi.org/10.1109/imtc.1997.603942

Karlsson, B. (1998). Fuzzy measures for sensor data fusion in industrial recycling. Measurement Science and Technology, 9(6), 907. https://doi.org/10.1088/0957-0233/9/6/007

Kijima, M. (1989). Some results for repairable systems with general repair. Journal of Applied probability, 26(1), 89-102. https://doi.org/10.1017/S0021900200041826

Kijima, M., Morimura, H., \& Suzuki, Y. (1988). Periodical replacement problem without assuming minimal repair. European Journal of Operational Research, 37(2), 194-203. https://doi.org/10.1016/03772217(88)90329-3

Kim, C.S., Djamaludin, I., \& Murthy, D.N.P. (2004). Warranty and discrete preventive maintenance. Reliability Engineering \& System Safety, 84(3), 301-309. https://doi.org/10.1016/j.ress.2003.12.001

Kim, D.K., Lim, J.H., \& Park, D.H., (2011). Optimal maintenance policies during the post-warranty period for second-hand item. The 2011 International Conference on Quality, Reliability, Risk, Maintenance, and Safety Engineering. 446-450. https://doi.org/10.1109/ICQR2MSE.2011.5976649

Klausner, M., Grimm, W.M., \& Hendrickson, C. (1998a). Reuse of electric motors in consumer products, Journal of Industrial Ecology, 2, 89-102. https://doi.org/10.1162/jiec.1998.2.2.89

Klausner, M., Grimm, W.M., Hendrickson, C., \& Horvath, A. (1998b). Sensor-based data recording of use conditions for product takeback, Proceedings of the IEEE International Symposium on Electronics and the Environment. Chicago, IL. 138-143. https://doi.org/10.1109/isee.1998.675046

Klausner, M., Grimm, W.M., \& Horvath, A. (1999). Integrating product takeback and technical service, Proceedings of the IEEE International Symposium on Electronics and the Environment. Danvers, MA. 48-53. https://doi.org/10.1109/isee.1999.765847

Kongar, E., \& Gupta, S.M. (2002). A multi-criteria decision making approach for disassembly-to-order systems, Journal of Electronics Manufacturing, 11, 171-183. https://doi.org/10.1142/S0960313102000345

Kongar, E., \& Gupta, S.M. (2006). Disassembly sequencing using genetic algorithm, International Journal of Advanced Manufacturing Technology, 30, 497-506. https://doi.org/10.1007/s00170-005-0041-x

Kongar, E., \& Gupta, S.M. (2009a). Solving the disassembly-to-order problem using linear physical programming. International Journal of Mathematics in Operational Research, 1(4), 504-531. 
Kongar, E., \& Gupta, S.M. (2009b). A multiple objective tabu search approach for end-of- life product disassembly. International Journal of Advanced Operations Management, 1(2-3), 177-202. https://doi.org/10.1504/IJAOM.2009.030672

Kuik, S.S., Kaihara, T., \& Fujii, N. (2015). Stochastic Decision Model of the Remanufactured Product with Warranty. Proceedings of the International MultiConference of Engineers and Computer Scientists (Vol. 2).

Lambert, A.J.D. \& Gupta, S.M. (2005). Disassembly Modeling for Assembly, Maintenance, Reuse, and Recycling. Boca Raton, FL: CRC Press.

Langella, I.M. (2007). Heuristics for demand-driven disassembly planning. Computers and Operations Research, 34, 552-577. https://doi.org/10.1016/j.cor.2005.03.013

Liao, B.F., Li, B.Y., \& Cheng, J.S. (2015). A warranty model for remanufactured products. Journal of Industrial and Production Engineering, 32(8), 551-558. https://doi.org/10.1080/21681015.2015.1090490

Lutz, N.A., \& Padmanabhan, V. (1995). Why do we observe minimal warranties? Marketing Science, 14(4), 417-441.

Martorell, S., Sanchez, A., \& Serradell, V. (1999). Age-dependent reliability model considering effects of maintenance and working conditions. Reliability Engineering \& System Safety, 64(1), 19-31.

Mazhar, M.I., Kara, S., \& Kaebernick, H. (2005). Reusability assessment of components in consumer products - A statistical and condition monitoring data analysis strategy, Proceedings of the 4th Australian LCA Conference. Sydney, Australia.

Mazhar, M.I., Kara, S., \& Kaebernick, H. (2007). Remaining life estimation of used components in consumer products: Life cycle data analysis by Weibull and artificial neural networks. Journal of Operations Management, 25, 1184-1193. https://doi.org/10.1016/j.jom.2007.01.021

Moyer, L.K., \& Gupta, S.M. (1997). Environmental concerns and recycling/disassembly efforts in the electronics industry. Journal of Electronics Manufacturing, 7, 1-22. https://doi.org/10.1142/S0960313197000026

Murthy, D.P., \& Blischke, W.R. (2006). Warranty management and product manufacture. London: Springer.

Naini, S.G.J., \& Shafiee, M. (2011). Joint determination of price and upgrade level for a warranted remanufactured product. The International Journal of Advanced Manufacturing Technology, 54, 1187-1198. https://doi.org/10.1007/s00170-010-2994-7

Nakagawa, T. (2006). Maintenance theory of reliability. Springer Science \& Business Media.

Nakagawa, T. (2008). Advanced reliability models and maintenance policies. Springer Science \& Business Media. 
Ondemir, O., Ilgin, M.A., \& Gupta, S.M. (2012). Optimal end-of-life management in closed-loop supply chains using RFID and sensors. Industrial Informatics, IEEE Transactions, 8(3), 719-728. https://doi.org/10.1109/TII.2011.2166767

Ondemir, O., \& Gupta, S.M. (2012). Optimal Management of Reverse Supply Chains with Sensor-Embedded End-of-Life Products. Applications of Management Science, 15, 109.

https://doi.org/10.1108/S0276-8976(2012)0000015009

Ondemir, O., \& Gupta, S.M. (2013). Advanced Remanufacturing-to-Order and Disassembly-to-Order System under Demand/Decision Uncertainty. Reverse Supply Chains: Issues and Analysis, 203.

Pecht, M. (2008). Prognostics and health management of electronics. John Wiley \& Sons, Ltd. https://doi.org/10.1002/9780470061626.shm118

Petriu, E.M., Georganas, N.D., Petriu, D.C., Makrakis, D., \& Groza, V.Z. (2000). Sensor-based information appliances, IEEE Instrumentation and Measurement Magazine, 3, 31-35. https://doi.org/10.1109/5289.887458

Saidi-Mehrabad, M., Noorossana, R., \& Shafiee, M. (2010). Modeling and analysis of effective ways for improving the reliability of remanufactured products sold with warranty. The International Journal of Advanced Manufacturing Technology, 46, 253-265. https://doi.org/10.1007/s00170-009-2084-x

Scheidt, L., \& Shuqiang, Z. (1994). An approach to achieve reusability of electronic modules, Proceedings of the IEEE International Symposium on Electronics and the Environment. San Francisco, CA. 331-336. https://doi.org/10.1109/isee.1994.337237

Shafiee, M., \& Chukova, S. (2013). Maintenance models in warranty: A literature review. European Journal of Operational Research, 229(3), 561-572. https://doi.org/10.1016/j.ejor.2013.01.017

Shafiee, M., Chukova, S., Yun, W.Y., \& Akhavan-Niaki, S.T. (2011a). On the investment in a reliability improvement program for warranted remanufactured items. IIE Transactions, 43, 525-534. https://doi.org/10.1080/0740817X.2010.540638

Shafiee, M., Finkelstein, M., \& Chukova, S. (2011b). On optimal upgrade level for used products under given cost structures. Reliability Engineering \& System Safety, 96, 286-291.

https://doi.org/10.1016/j.ress.2010.07.008

Sharma, A., Yadava, G.S., \& Deshmukh, S.G. (2011). A literature review and future perspectives on maintenance optimization. Journal of Quality in Maintenance Engineering, 17(1), 5-25.

https://doi.org/10.1108/13552511111116222 
Simon, M., Bee, G., Moore, P., Pu, J.-S. \& Xie, C. (2001). Modelling of the life cycle of products with data acquisition features. Computers in Industry, 45, 111-122. https://doi.org/10.1016/S0166-3615(01)00088-4

Soberman, D.A. (2003). Simultaneous signaling and screening with warranties. Journal of Marketing Research, 40(2), 176-192. https://doi.org/10.1509/jmkr.40.2.176.19228

Spence, M. (1977). Consumer misperceptions, product failure and producer liability. The Review of Economic Studies, 561-572. https://doi.org/10.2307/2296908

Taguchi, G. (1986). Orthogonal Arrays and Linear Graphs. Dearborn, ML: American Supplier Institute, Inc.,

Vadde S., Kamarthi S.V., Gupta S.M., \& Zeid, I. (2008). Product life cycle monitoring via embedded sensors. In: Gupta, SM, \& Lambert A.J.D. (Eds.). Environment conscious manufacturing (91-103). Boca Raton: CRC Press.

Wang, H. (2002). A survey of maintenance policies of deteriorating systems. European journal of operational research, 139(3), 469-489. https://doi.org/10.1016/S0377-2217(01)00197-7

Yang, X., Moore, P., \& Chong, S.K. (2009b). Intelligent products: From lifecycle data acquisition to enabling product-related services. Computers in Industry, 60, 184-194.

https://doi.org/10.1016/j.compind.2008.12.009

Yang, X., Moore, P., Pu, J.-S., \& Wong, C.-B. (2009c). A practical methodology for realizing product service systems for consumer products. Computers and Industrial Engineering, 56, 224-235. https://doi.org/10.1016/j.cie.2008.05.008

Yazdian, S.A., Shahanaghi, K., \& Makui, A. (2014). Joint optimisation of price, warranty and recovery planning in remanufacturing of used products under linear and non-linear demand, return and cost functions. International Journal of Systems Science, 47(5), 1155-1175.

https://doi.org/10.1080/00207721.2014.915355

Yeh, R.H., Lo, H.C., \& Yu, R.Y. (2011). A study of maintenance policies for second-hand products. Computers \& Industrial Engineering, 60(3), 438-444. https://doi.org/10.1016/j.cie.2010.07.033

Journal of Industrial Engineering and Management, 2017 (www.jiem.org)

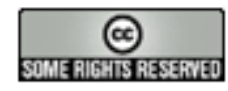

Article's contents are provided on an Attribution-Non Commercial 3.0 Creative commons license. Readers are allowed to copy, distribute and communicate article's contents, provided the author's and Journal of Industrial Engineering and Management's names are included. It must not be used for commercial purposes. To see the complete license contents, please visit http://creativecommons.org/licenses/by-nc/3.0/. 